\title{
Experimental Characterization of the Influence of Nozzle Temperature in FDM 3D Printed Pure PLA and Advanced PLA+
}

\author{
Mohammad S. Alsoufi", Mohammed W. Alhazmi, Dhia K. Suker, Turki A. Alghamdi, \\ Rayan A. Sabbagh, Mohammed A. Felemban, Feras K. Bazuhair \\ Department of Mechanical Engineering, College of Engineering and Islamic Architecture, Umm Al-Qura University, Makkah, KSA \\ *Corresponding author: mssoufi@uqu.edu.sa
}

Received January 13, 2019; Revised February 20, 2019; Accepted April 01, 2019

\begin{abstract}
This paper experimentally observed at a small level the influence of nozzle temperature change on warping deformation (WD), dimensional Accuracy (DA) and density. The materials chosen are pure PLA and advanced PLA+ specimens of rectangular shape of $63.5 \mathrm{~mm} \times 9.53 \mathrm{~mm} \times 3.2 \mathrm{~mm}$ produced by the end-user 3D printer based on fused deposition modeling (FDM). During the printing work, the nozzle temperature was conducted at twelve different values $195^{\circ} \mathrm{C}$ to $250^{\circ} \mathrm{C}$ with $5^{\circ} \mathrm{C}$ increments. Additionally, the infill density was set at $20 \%$ along with infill line direction of $0^{\circ}, 90^{\circ}, 45^{\circ}$ and $\pm 45^{\circ}$. After the fabrication, the FDM 3D printed parts naturally cooled down to room temperature at $T=23 \pm 2^{\circ} \mathrm{C}$. As a result, the higher the nozzle temperature, the lower the deformed shape errors (with low uncertainty) of the specimens were. Experimental results show that the measured dimensions are always more than the original CAD file dimension along the height but less than the original CAD file dimensions along the width and length. The density measurements of both materials at $90^{\circ}$ infill line direction have higher values compared with other directions $\left(0^{\circ}, 45^{\circ}, \pm 45^{\circ}\right)$, which have very similar results. The data and knowledge obtained from this investigation can be helpful for both an academic and an industrial perspective to set optimum nozzle temperature at small scale level and also it can be used to fabricate low-cost functional objects. Furthermore, it will also allow us to redesign the original CAD file in order to compensate the warping deformation encountered when using end-user FDM 3D additive manufacturing.
\end{abstract}

Keywords: nozzle temperature, PLA, PLA+, FDM, dimensional accuracy, warping deformation

Cite This Article: Mohammad S. Alsoufi, Mohammed W. Alhazmi, Dhia K. Suker, Turki A. Alghamdi, Rayan A. Sabbagh, Mohammed A. Felemban, and Feras K. Bazuhair, "Experimental Characterization of the Influence of Nozzle Temperature in FDM 3D Printed Pure PLA and Advanced PLA+." American Journal of Mechanical Engineering, vol. 7, no. 2 (2019): 45-60. doi: 10.12691/ajme-7-2-1.

\section{Introduction}

\subsection{Background}

Worldwide, in modern manufacturing industries, the attention to maximizing productivity has been one of the set performance targets for an extended period [1]. In order to achieve higher printing quality products with suitability for market applications, greater efficiency and direct reduction of costs, as well as an ability to comply with environmental requirements along with a subsequently faster new product development process and quicker span timeline to the client, modern manufacturing industries have endeavored to apply more computerintegrated automation systems (i.e., which encompasses time investment in learning the software and hardware) [2]. One of the latest non-conventional technologies to have made an important step over the last two decades or so is additive manufacturing (AM) techniques $[3,4]$. The 3D printing is a subset of AM. ASTM international defines AM under standard terminology, ASTM F2792-12a, June 2010 [5] as the "a process of joining materials to make objects from 3D model data, usually layer upon layer, as opposed to subtractive manufacturing methodologies."

Fused deposition modeling (FDM, developed in the 1980s [6] and commercialized in 1990 [7]) is additive manufacturing (AM) technologies that build automatically three-dimensional (3D) physical parts by heating up and extruding down the thermoplastic filaments materials through a small nozzle, without any tooling or machining $[8,9,10]$ and also by eliminating the need for human interventions [11]. They are not only used to fabricate prototypes, but final products are also manufactured with these types of machines [12] with a dimensional tolerance equal to $\pm 1 \mathrm{~mm}$ overall [13]. These are all additive manufacturing processes which differ primarily from the normal subtractive process (conventional machine), by which a bulk material (traditional engineering material) is machined to reach the desired 3D physical shape [14]. Furthermore, the growing demand for product diversity 
and customized products are also favouring the growth of AM $[14,15]$.

Similarly to many other AM systems, the generated 3D design can interact with a computer-aided design (CAD) file via STL format (an abbreviation of "stereolithography," developed for a stereolithography machine in 1988) [16], either by creating the 3D model or scanned with a 3D scanner. The small heated extrusion nozzle follows computer controlled paths as in computer numerical control (CNC) using G-code commands compatible with the FDM 3D device and uploaded to the FDM 3D machine through its SD card/USB port [17] while extruding molten thermoplastic filaments materials horizontally at defined positions on a printing build plate to draw layers or paths (layer-by-layer or path-by-path) on top of another to build a 3D physical part [18]. Additionally, FDM 3D modeling computer software (firmware) performs mathematically slicing (.stl file), orienting and patching the model for the building process at a temperature above its melting point [19]. This extrusion of multiple layers or paths of thermoplastic filament material is formed from contour raster called shells, which are filled with infill raster. Typically, the two-dimensional (2D) tool path prepared using a slicing software starts by fusing the contours that outline the layers. Depending on the slicing open source software application (i.e., Simplify3D ${ }^{\circledR}$, Ultimaker Cura 3D ${ }^{\circledR}$, Slic3r ${ }^{\circledR}$, and so on), the number of contours can be specified either by inputting the contours' number or the shell thickness and then automatically the contours' number will be calculated by defining their thickness. After printing the outlines, the single-extruder machine fills the area inside the contours with infill density patterns (i.e., grid, lines, triangles, tri-hexagon, cubic, cubic subdivision, octet, quarter cubic, concentric, concentric $3 \mathrm{D}$, zigzag, cross and cross 3D) and the negative gap between each raster can be defined, which is called the overlap [20]. Up to date, FDM 3D technology can be implemented practicably even on an individual or household level [21] using conventional software and hardware [22], all of which is monitored by an open-source micro-controller [23].

\subsection{Motivation and Contributions}

Similarly to other manufacturing methods, the quality finish of additively manufactured parts is subject to process parameter limitations and machine imprecision. One of the primary sources of FDM 3D printed part inaccuracy in an open source end-user FDM 3D printer is the fact that the thermoplastic filaments materials that come out from its small extruding nozzle tend to shrink (warp) and sometimes a few layers peel away from the printer's build plate, mainly in corners, due to its solidification temperature, though they provide conceivably low-cost alternatives to conventional machining. In this regard, this high degree of warping deformation in an enduser FDM 3D printer during the cooling process, which does not occur uniformly along the different axis, has been highlighted by several researchers at large scale (macro level) $[11,15,24,25,26]$. Other challenges of increasing the percentage of the final products with AM in the industry is the lower dimensional accuracy of these technologies compared to the subtractive manufacturing processes (turning, milling, boring, broaching, drilling, grinding, and so on). People extensively using AM technologies for their final products are aware of this limitation.

If the warping deformation is not controlled, the printing material cannot adhere to the printing bed, and further prints cannot be executed. Hence, the purpose of this research paper is to study the warping deformation (WD) and dimensional accuracy (DA) at small scale level using polylactic acid pure (PLA) and advanced (PLA+) engineering printed thermoplastic filament material and to establish the best manufacturing process parameter value for the nozzle temperature. Furthermore, the density variation is also studied in a $3 \mathrm{D}$ printer on the shape errors of pure PLA and advanced PLA+ parts caused by the heat shrinkage in the FDM-AM (Fused Deposition ModelingAdditive Manufacturing).

\section{Materials and Methods}

In this section, the materials, equipment, size, dimension, design, fabrication and process parameters conditions used in the production of the printed samples are described in detail in the following sub-sections.

\subsection{FDM 3D Material}

In the present research, commercial and inexpensive printing thermoplastic filament materials polylactic acid pure (PLA) and advanced (PLA + ) were purchased from eSUN (around \$25 for one kilogram of spool) which was initially founded in Shenzhen, China [27], with the filament diameter of $1.75 \mathrm{~mm}$ and was used as received. Additionally, pure PLA (with a density of $\sim 1.24 \mathrm{~g} / \mathrm{cm}^{3}$ and a melt flow rate of $5 \mathrm{~g} 10^{-1} \mathrm{~min}^{-1}\left(190^{\circ} \mathrm{C}, 2.16 \mathrm{Kg}\right)$ ) and advanced PLA+ (with a density of $\sim 1.24 \mathrm{~g} / \mathrm{cm}^{3}$ and a melt flow rate of $\left.2 \mathrm{~g} 10^{-1} \mathrm{~min}^{-1}\left(190^{\circ} \mathrm{C}, 2.16 \mathrm{Kg}\right)\right)$ are biocompatible, biodegradable, non-toxic, nonimmunogenic and non-inflammatory properties derived from lactic acid [2,27]. The main advantage of this thermoplastic filament material is how easy it is to use in $3 \mathrm{D}$ printing and the good results it delivers. The reason for choosing, in this study, to investigate pure PLA and advanced PLA + over other thermoplastic filament materials is primarily a practical one since both materials worked with our FDM 3D printer very effectively.

\subsection{FDM 3D Printer Device}

The end-user FDM 3D printer used was a single spool of thermoplastic filament material Original Prusa I3 MK3 purchased from PRUSA RESEARCH, Prague, Czech Republic. The maximum printing size was $25 \times 21 \times 21$ $\mathrm{cm}$ (length, width and height, respectively) and 11,025 $\mathrm{cm}^{3}$ build volume. Furthermore, 1715 steps to move $1 \mathrm{~mm}$ of the thermoplastic filament material through the extruder and into the hot end, thanks to the stepper motor with 200 steps/revolution and 256 micro-steps which giving 51200 step/revolution. Noted that the circumference of the circle was $29.845 \mathrm{~mm}$. 


\subsection{FDM 3D Size and Dimension}

The CAD design was drawn and visualized in Autodesk ${ }^{\circledR}$ Inventor Professional 2019 software (rectangular 3D shape with $63.5 \mathrm{~mm}$ length, $9.53 \mathrm{~mm}$ width and $3.20 \mathrm{~mm}$ height) and transferred to the 3D printable format using the Cura ${ }^{\circledR}$ software as shown in Figure 1. The Ultimaker Cura $^{\circledR} 3.6$ edition (www.ultimaker.com) was used to generate the machine code for the end-user FDM 3D printer from the $3 \mathrm{D}$ model file. Bear in mind that the specimen dimension for length (L), width (W) and height $(\mathrm{H})$ was adapted from ASTM D638-10 Type V (micro-scale), as there are not specific test standards for printed materials. Noted that this is the Type V specimen, used for tensile testing under the ASTM D638-10 standard.

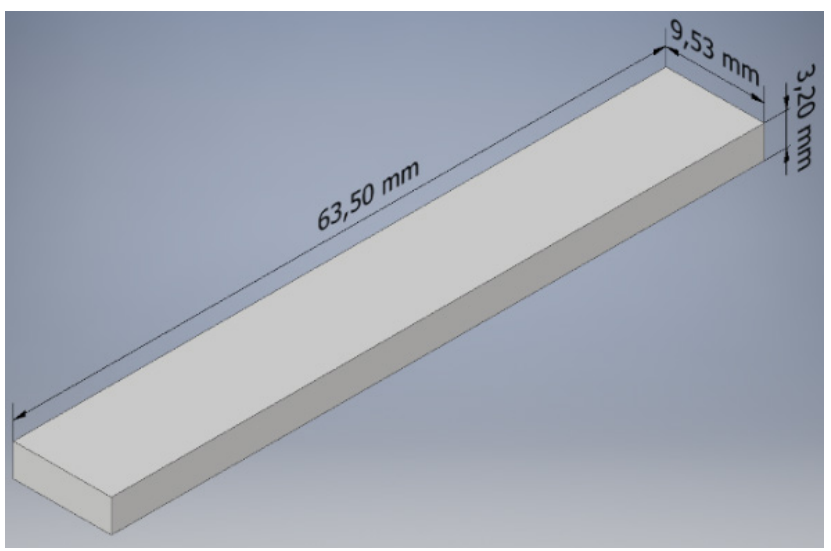

Figure 1. The end-user FDM 3D printer and 3D physical rectangular shape

\subsection{FDM 3D Design and Fabrication}

The FDM 3D printed parts have been designed and fabricated of a total of 96 specimens at small scale level as shown in Figure 2. The $z$-axis represents the build direction and the $x-y$ plane is parallel to the build platform. Figure 3 shows the FDM 3D printed object using volume fraction of $20 \%$ infill density for both pure PLA (grey) and advanced PLA+ (blue) thermoplastic filament material with different infill line direction of $0^{\circ}, 90^{\circ}, 45^{\circ}$ and $\pm 45^{\circ}$. The infill density was set at $20 \%$ meaning that the physical shape with an infill structure could print in approximately one fourth the time of a full solid physical shape. In general, all infill line direction showed the same print time while $\pm 45^{\circ}$ shows slightly more print time for the same density (this is less true for a system such as SLA where the entire layers are exposed at once). A line pattern was chosen in order to generate a random infill pattern with linear connections between the walls. A total of 96 printed parts were fabricated with nozzle temperature as an independent variable ranging from $195^{\circ} \mathrm{C}$ to $250^{\circ} \mathrm{C}$ with $5^{\circ} \mathrm{C}$ increments while other process parameters were kept constant. Since the 3D physical shape properties of pure PLA and advanced PLA+ can vary depending on the ambient temperature and relative humidity, all tests were carried out according to the standards for room temperature and relative humidity. Finally, the $3 \mathrm{D}$ printing parameters of deposition line height and width were kept the same in all specimens. Therefore, it is possible to think that the experiments were all made upon a material of uniform microstructure, placed at specific orientations, following the FDM deposition.

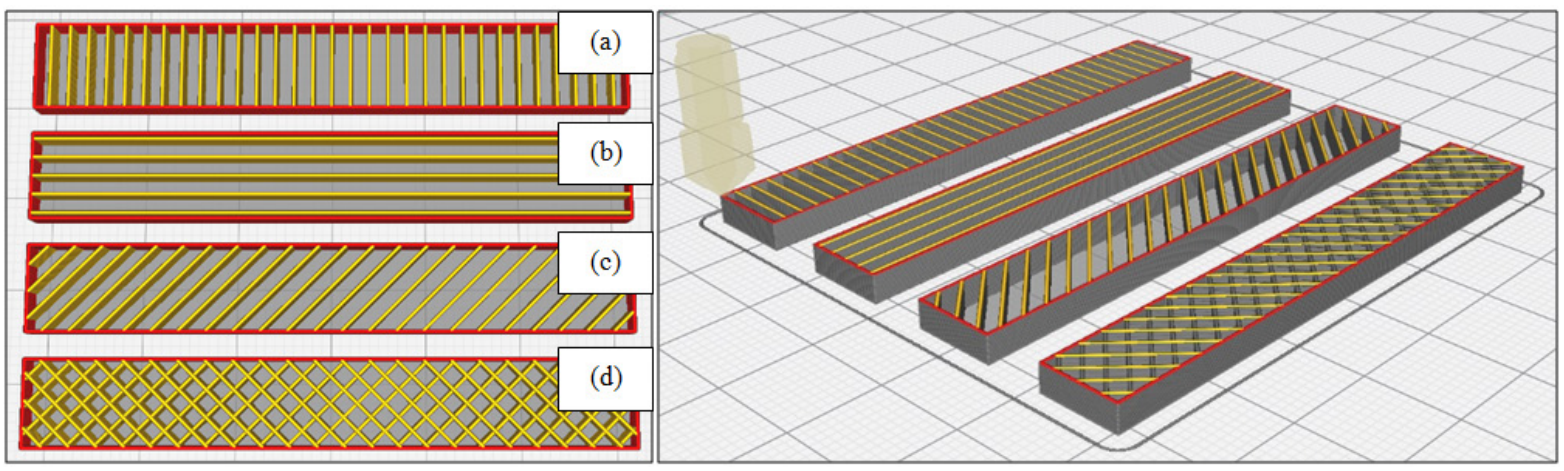

Figure 2. The FDM 3D printed object using $20 \%$ infill density pure PLA and advanced PLA+ thermoplastic filament material with different infill line direction of (a) $0^{\circ}$, (b) $90^{\circ}$, (c) $45^{\circ}$ and (d) $\pm 45^{\circ}$ and nozzle temperature ranging from $195^{\circ} \mathrm{C}$ to $250^{\circ} \mathrm{C}$ with $5^{\circ} \mathrm{C}$ increments

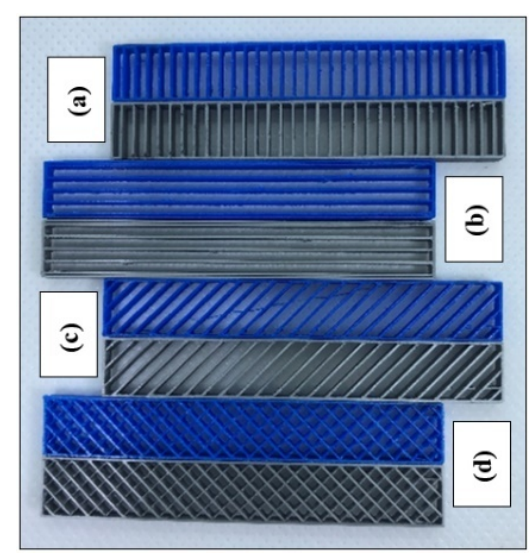

Figure 3. The FDM 3D printed object using $20 \%$ infill density pure PLA (grey) and advanced PLA+ (blue) thermoplastic filament material with different infill line direction of (a) $0^{\circ}$, (b) $90^{\circ}$, (c) $45^{\circ}$ and (d) $\pm 45^{\circ}$ 


\subsection{FDM 3D Process Parameters}

The manufacturing process parameters were selected according to the lack of information in the literature review, industrial and academic experience and the acceptable range specified by Stratasys (the main manufacturer for end-user FDM 3D machines). First, all specimens were 3D printed using pure PLA and advanced PLA + thermoplastic filament material. Second, the layers (paths) followed specific orientations (infill line direction) $0^{\circ}, 90^{\circ}, 45^{\circ}$ and $\pm 45^{\circ}$. Third, the printing nozzle temperature ranged from $195^{\circ} \mathrm{C}$ to $250^{\circ} \mathrm{C}$ with $5^{\circ} \mathrm{C}$ increments. Figure 4 shows the temperature scale of pure PLA and advanced PLA+ thermoplastic filament material ranging from $195^{\circ} \mathrm{C}$ to $250^{\circ} \mathrm{C}$ with $5^{\circ} \mathrm{C}$ increments including the manufacture recommendation best print temperature. Finally, the 3D printing process parameters of deposition were kept the same and controlled in all FDM 3D specimens by applying build plate temperature of $60^{\circ} \mathrm{C}$ and without epoxy resin adhesive on the platform (print bed). Therefore, it is conceivable that the experiments were all completed upon a material of a constant microstructure-based nature, placed at specific orientations, following the FDM deposition. Table 1 lists the exact processing parameters for each printed sample. Before the process begins, it is necessary to set up the FDM 3D machine, which often includes pre-heating the extruder and print bed in order to stabilize the FDM 3D machine and flow properties of the thermoplastic filament material before printing begins. This ensures more consistent properties and prevents problems with clogs and extrusion gaps.

Table 1. Printing process parameters and their levels used in this work

\begin{tabular}{|c|c|c|c|}
\hline Setting & Parameters & Unit & Values \\
\hline Quality & Layer Height & $\mathrm{mm}$ & 0.1 \\
\hline \multirow{7}{*}{ Shell } & Wall Thickness & $\mathrm{mm}$ & 0.4 \\
\hline & Wall Line Count & - & 1 \\
\hline & Top/Bottom Thickness (mm) & $\mathrm{mm}$ & \multirow{5}{*}{0} \\
\hline & Top Thickness & $\mathrm{mm}$ & \\
\hline & Top Layer & - & \\
\hline & Bottom Thickness & $\mathrm{mm}$ & \\
\hline & Bottom Layer & - & \\
\hline \multirow{5}{*}{ Infill } & Infill Density & $\%$ & $\begin{array}{c}20 \\
\text { Line }\end{array}$ \\
\hline & Infill Pattern & - & Line \\
\hline & Infill Line Direction & $\circ$ & \pm 45 \\
\hline & Infill Overlap Percentage & $\%$ & 25 \\
\hline & Infill Layer Thickness & $\mathrm{mm}$ & 0.1 \\
\hline \multirow{4}{*}{ Nozzle } & Nozzle Size & $\mathrm{mm}$ & 0.4 \\
\hline & Compatible Material Diameter & $\mathrm{mm}$ & 1.75 \\
\hline & Nozzle Offset $x$-axis & $\mathrm{mm}$ & \multirow{2}{*}{0} \\
\hline & Nozzle Offset $y$-axis & $\mathrm{mm}$ & \\
\hline \multirow{14}{*}{ Material } & Filament Type & - & advanced PLA+ \\
\hline & Filament Colour & - & Grey \\
\hline & AM Process & - & FDM (Fused Deposition Modeling) \\
\hline & Printing Direction & - & Flat on Platform (on Printing Table) \\
\hline & Printing Temperature & ${ }^{\circ} \mathrm{C}$ & \multirow{4}{*}{$\begin{array}{l}195,200,205,210,215,220,225,230,235,240,245 \text { and } \\
250\end{array}$} \\
\hline & Printing Temperature Initial Layer & ${ }^{\circ} \mathrm{C}$ & \\
\hline & Initial Printing Temperature & ${ }^{\circ} \mathrm{C}$ & \\
\hline & Final Printing Temperature & ${ }^{\circ} \mathrm{C}$ & \\
\hline & Build Plate Temperature & ${ }^{\circ} \mathrm{C}$ & \multirow{2}{*}{60} \\
\hline & Build Plate Temperature Initial Layer & ${ }^{\circ} \mathrm{C}$ & \\
\hline & Flow & $\%$ & \multirow{2}{*}{100} \\
\hline & Initial Layer Flow & $\%$ & \\
\hline & Retraction Distance & $\mathrm{mm}$ & 0.8 \\
\hline & Retraction Speed & $\mathrm{mm} / \mathrm{s}$ & 35 \\
\hline \multirow{7}{*}{ Speed } & Print Speed & $\mathrm{mm} / \mathrm{s}$ & \multirow{2}{*}{30} \\
\hline & Infill Speed & $\mathrm{mm} / \mathrm{s}$ & \\
\hline & Wall Speed & $\mathrm{mm} / \mathrm{s}$ & \multirow{2}{*}{15} \\
\hline & Outer Wall Speed & $\mathrm{mm} / \mathrm{s}$ & \\
\hline & Inner Wall Speed & $\mathrm{mm} / \mathrm{s}$ & 30 \\
\hline & Top/Bottom Speed & $\mathrm{mm} / \mathrm{s}$ & \multirow{2}{*}{15} \\
\hline & Initial Layer Sped & $\mathrm{mm} / \mathrm{s}$ & \\
\hline Cooling & Fan Speed (\%) & $\%$ & 100 \\
\hline \multirow{4}{*}{$\begin{array}{l}\text { Build Plate } \\
\text { Adhesion }\end{array}$} & Build Plate Adhesion Type & - & Skirt \\
\hline & Skirt Lin Count & - & 1 \\
\hline & Skirt Distance & $\mathrm{mm}$ & 3 \\
\hline & Skirt/Brim Minimum Length & $\mathrm{mm}$ & 250 \\
\hline \multirow{2}{*}{$\begin{array}{c}\text { Environmental } \\
\text { Condition }\end{array}$} & Room Temperature & ${ }^{\circ} \mathrm{C}$ & $23 \pm 2$ \\
\hline & Relative Humidity & $\% \mathrm{RH}$ & $50 \pm 10$ \\
\hline
\end{tabular}




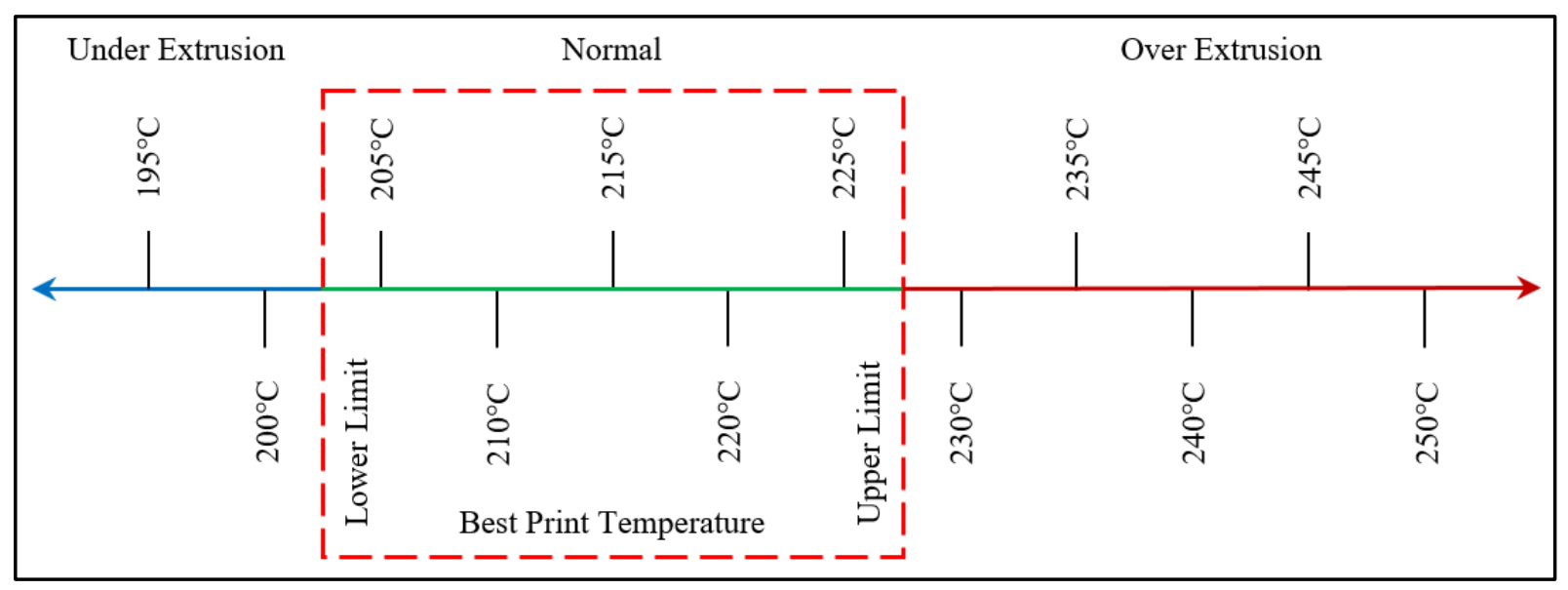

Figure 4. Temperature scale of pure PLA and advanced PLA+ thermoplastic filament material ranging from $195^{\circ} \mathrm{C}$ to $250^{\circ} \mathrm{C}$ with $5^{\circ} \mathrm{C}$ increments including the manufacture recommendation best print temperature

\subsection{FDM 3D Test Specimens Measurement}

The FDM 3D fabricated part is measured in terms of length (L), width (W) and height $(\mathrm{H})$ directions using a digital Vernier caliper device. From this observation, dimensional accuracy (DA) is calculated which is equal to the absolute value of each measured value minus the theoretical value and then averaged. Similarly, warping deformation (WD) is also measured, respectively, at the four corners including that the middle and the average value is noted down using the same precision instrument. A total of 96 FDM 3D printed samples are collected from the study measuring these performance characteristics (warp deformation $(\mu \mathrm{m})$, dimensional accuracy $(\mu \mathrm{m})$ and density $\left.\left(\mathrm{g} / \mathrm{cm}^{3}\right)\right)$. Figure 5 shows the warping deformation and its method of measurement.

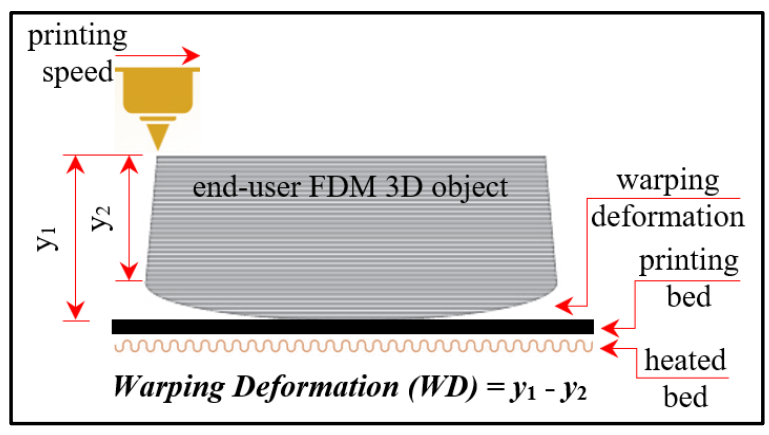

Figure 5. Warping deformation and its method of measurement at each corner

For repeatability and reproducibility measurements, each corner of 96 FDM 3D printed parts including the middle was measured at least three times, and the average value was considered according to Equation (1) to Equation (5), and the overall warping deformation error was also calculated using Equation (6).

$$
\begin{aligned}
& \text { Error }_{1}=\frac{T V-M V_{1}}{T V} \times 100 \\
& \text { Error }_{2}=\frac{T V-M V_{2}}{T V} \times 100 \\
& \text { Error }_{3}=\frac{T V-M V_{3}}{T V} \times 100
\end{aligned}
$$

$$
\begin{aligned}
& \text { Error }_{4}=\frac{T V-M V_{4}}{T V} \times 100 \\
& \text { Error }_{5}=\frac{T V-M V_{5}}{T V} \times 100 \\
& \text { Overall WD Error }=\frac{1}{5} \sum_{i=1}^{5} \text { Error }_{i}
\end{aligned}
$$

Where TV indicated the true value, which was set at the original CAD file and MV indicated the measured value which was obtained after the FDM 3D printed parts were created. Noted that MV1 represents the measured value at corner $1, \mathrm{MV} 2$ represents the measured value at corner 2, MV3 represents the measured value at corner 3, MV4 represents the measured value at corner 4, and finally, MV5 represents the measured value in the middle. This precise and adequate method of measuring, from Equation (1) to Equation (6) was used to avoid any misalignment in the FDM 3D platform and also to negate any uncertainty appearing in the actual measured value of the geometry and any error that might appear in the first layer of building the 3D physical shape. Moreover, the density is also calculated by taking into account the mass and volume. The mass was acquired by weighing each sample after printing, and the volume was acquired measuring the height, length and width.

Prior to undergoing the measurement, a standard calibration procedure was carried outl using the digital Vernier gauge (rectangular block gauges, Slip Gauges) M112 (grade 0 , tolerance $\pm 0.04 \mu \mathrm{m}$ ) with a surface finish of less than $50 \mathrm{~nm}$. For our convenience, five calibration trials were performed. The results showed that the relationship between the input data (Slip Gauge dimension) and output data (reading in the digital Vernier gauge) was a linear relationship $\left(R^{2}>0.999\right)$ with $99.7 \%$, providing a level of confidence and coverage factor, $k=3$. This result is adequate enough to provide the required precise data as these trials procedures are predominantly concerned with related behaviour and mechanical design interpretation to other mechanical systems is always vulnerable to variations in thermoplastic materials and dimensions. 


\section{Performance Analysis of Warping Deformation, Dimensional Accuracy and Density}

To investigate the WD, DA and density by FDM 3D printing, different series of experimental design were carried out. Each measured value of warping deformation and dimensional accuracy is measured at least three times at different locations $(\sim 100 \mu \mathrm{m}$ away from the previous one), and the mean value is considered. Standard deviation $( \pm \mathrm{SD})$ for each measured value of warping deformation and dimensional accuracy is calculated and presented as standard deviation (mean $\pm \mathrm{SD}$ ) provides valuable results. The density is also measured accordingly. The error (uncertainty) for each length (L), width (W) and height $(\mathrm{H})$ and the overall error is also considered. The experimental observations and the percentage deviations are discussed in the following sub-section. All FDM 3D samples taken in this trial have more or less warping deformation around each corner as well as dimensional accuracy and densities. The data were analyzed using OriginLab $^{\circledR} 2019$ software.

\subsection{Performance Analysis of Warping Deformation (WD)}

In the first phase of the experimentations, the specimens were subjected to studying the warping deformation at each corner including consideration of the middle and the average. The warping deformation phenomenon happens as the adhesion of the first layer did not stick very well and peeled away from the build platform in the FDM 3D printer (hence forcing the structure to curl upward). The main reason for inhomogeneous warping of the printed parts in the FDM $3 \mathrm{D}$ printing process is due to time being delayed for the solidification of the first layer and other layers. Moreover, the problem is caused by force transmission between the first layer and other layers owing to the phase of change from molten plastic to solid during the building process. Some of the examples of warping deformation problems which occur in the FDM 3D process are pincushion, trapezoid, curling and blocked shrinkages [1]. Figure 6 shows the original CAD file of the FDM 3D printed part target for warping analysis.

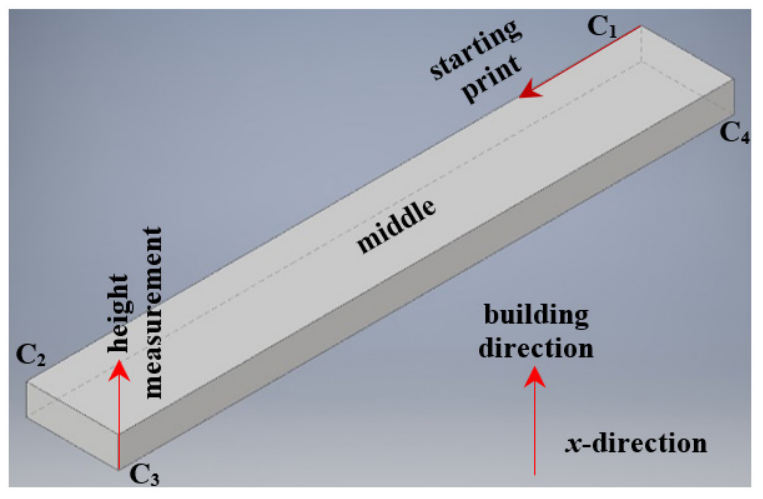

Figure 6. $\mathrm{CAD}$ file of printed part for warping analysis

Figure 7 shows the height measurements (warping deformation analysis) for both pure PLA and advanced
PLA+ without adding epoxy resin adhesive on the platform (print bed). In this trial, the nozzle temperature ranges from $195^{\circ} \mathrm{C}$ (under extrusion) to $250^{\circ} \mathrm{C}$ (over extrusion) and there is a different infill line direction of $0^{\circ}$, $90^{\circ}, 45^{\circ}$ and $\pm 45^{\circ}$. In general, pure PLA shows non-uniform distribution variation and suffers greatly from warping in the corners on overall height measurements whereas advanced PLA+ shows almost uniform distribution on overall height measurements under the same dependent and independent manufacturing process parameters, except under extrusion for $90^{\circ}$ infill line direction.

For pure PLA as shown in Figure 7(a), the mean and standard deviation of the height measurements were $3.289 \pm 0.020 \mathrm{~mm}$ (for $0^{\circ}$ ), $3.251 \pm 0.046 \mathrm{~mm}$ (for $90^{\circ}$ ), $3.259 \pm 0.042 \mathrm{~mm}$ (for $45^{\circ}$ ) and $3.281 \pm 0.017 \mathrm{~mm}$ (for $\pm 45^{\circ}$ ) with minimum and maximum mean height measurements of $3.269 \pm 0.007 \mathrm{~mm}$ and $3.315 \pm 0.055 \mathrm{~mm}$ (for $0^{\circ}$ ), $3.127 \pm 0.011 \mathrm{~mm}$ and $3.291 \pm 0.188 \mathrm{~mm}$ (for $90^{\circ}$ ), $3.147 \pm 0.006 \mathrm{~mm}$ and $3.320 \pm 0.173 \mathrm{~mm}$ (for $45^{\circ}$ ) and $3.212 \pm 0.005 \mathrm{~mm}$ and $3.323 \pm 0.070 \mathrm{~mm}$ (for $\pm 45^{\circ}$ ), respectively. This indicates a consistently high degree of a precision and a highly accurately measuring system with $97.222 \%$ (for $0^{\circ}$ ), $98.422 \%$ (for $90^{\circ}$ ), $98.161 \%$ (for $45^{\circ}$ ) and $97.462 \%$ (for $\pm 45^{\circ}$ ), providing a level of confidence and the total coverage factor of $k=3$ as overall and with minimum and maximum percentage of $96.417 \%$ and $97.854 \%$ (for $0^{\circ}$ ), $97.146 \%$ and $98.422 \%$ (for $90^{\circ}$ ), $96.250 \%$ and $98.161 \%$ (for $45^{\circ}$ ) and $96.146 \%$ and $99.625 \%$ (for $\pm 45^{\circ}$ ), respectively. All systematic errors (caused by incorrect calibration of the measuring instrument) were almost eliminated only random errors (caused by the accuracy limit of the measuring instrument) were calculated by $2.778 \%$ (for $0^{\circ}$ ), $1.578 \%$ (for $90^{\circ}$ ), $1.839 \%$ (for $45^{\circ}$ ) and $2.538 \%$ (for $\pm 45^{\circ}$ ) with minimum and maximum percentage of $2.146 \%$ and $3.583 \%$ (for $0^{\circ}$ ), $1.578 \%$ and $2.854 \%$ (for $90^{\circ}$ ), $1.839 \%$ and $3.750 \%$ (for $45^{\circ}$ ) and $0.375 \%$ and $3.854 \%$ (for $\pm 45^{\circ}$ ), respectively, under different nozzle temperatures. It is interesting to notice that more than $100 \%$ accuracy and error with a negative value indicating the printed parts exceed the true value of the original STL file, which means more stretch at the printing direction especially at $90^{\circ}$ and $45^{\circ}$ infill line direction as the surface area is too large. Contrariwise, the inflation did not exceed the true value of the STL file at $0^{\circ}$ and $\pm 45^{\circ}$, indicating that a short path of printing layer is more effective for the internal structure and did not change the properties substantially. So, this is a dimensional inaccuracy.

For advanced PLA+ as shown in Figure 7(b), the mean and standard deviation of the height measurements were $3.297 \pm 0.037 \mathrm{~mm}\left(\right.$ for $0^{\circ}$ ), $3.227 \pm 0.053 \mathrm{~mm}$ (for $90^{\circ}$ ), $3.298 \pm 0.022 \mathrm{~mm}$ (for $45^{\circ}$ ) and $3.289 \pm 0.018 \mathrm{~mm}\left(\right.$ for $\pm 45^{\circ}$ ) with minimum and maximum mean height measurements of $3.223 \pm 0.007 \mathrm{~mm}$ and $3.347 \pm 0.140 \mathrm{~mm}$ (for $0^{\circ}$ ), $2.769 \pm 0.006 \mathrm{~mm}$ and $3.308 \pm 0.320 \mathrm{~mm}$ (for $90^{\circ}$ ), $3.239 \pm 0.007 \mathrm{~mm}$ and $3.331 \pm 0.076 \mathrm{~mm}$ (for $45^{\circ}$ ) and $3.241 \pm 0.006 \mathrm{~mm}$ and $3.324 \pm 0.067 \mathrm{~mm}$ (for $\pm 45^{\circ}$ ), respectively. This indicates a consistently high degree of precision and a highly accurate measuring system with $96.960 \%$ (for $0^{\circ}$ ), $99.169 \%$ (for $90^{\circ}$ ), $96.946 \%$ (for $45^{\circ}$ ) and $97.223 \%$ (for $\pm 45^{\circ}$ ), providing a level of confidence and the total coverage factor of $k=3$ as overall and with minimum and maximum percentages of $95.417 \%$ 
and $99.281 \%$ (for $0^{\circ}$ ), $96.625 \%$ and $99.169 \%$ (for $90^{\circ}$ ), $95.896 \%$ and $98.792 \%$ (for $45^{\circ}$ ) and $96.125 \%$ and $98.708 \%$ (for $\pm 45^{\circ}$ ), respectively. All systematic errors (caused by incorrect calibration of the measuring instrument) were almost eliminated only random errors (caused by the accuracy limit of the measuring instrument) were calculated by $3.327 \%$ (for $0^{\circ}$ ), $0.831 \%$ (for $90^{\circ}$ ), $3.054 \%$ (for $45^{\circ}$ ) and $2.777 \%$ (for $\pm 45^{\circ}$ ) with minimum and maximum percentage of $0.719 \%$ and $4.583 \%$ (for $0^{\circ}$ ), $3.283 \%$ and $3.375 \%$ (for $90^{\circ}$ ), $1.208 \%$ and $4.104 \%$ (for $45^{\circ}$ ) and $1.292 \%$ and $3.875 \%$ (for $\pm 45^{\circ}$ ), respectively, under different nozzle temperatures. Again, 100\% accuracy and error with a negative value are also noticeable. The resulting geometry was slightly oversized compared with the nominal geometry. The error in accuracy in the final printed parts with different infill line direction arises from the shrinkage during cooling and solidification or warping process as uneven heat distribution creates internal stresses within a part. An environmental chamber to control the temperature and humidity during the drying process might lead to preventing the warping and the formation of cracks during the drying process.

Figure 8 shows the performance of pure PLA versus advanced PLA + at $0^{\circ}, 90^{\circ}, 45^{\circ}$ and $\pm 45^{\circ}$ infill line direction with $20 \%$ infill density. Three different zones were examined namely under extrusion, normal extrusion and over extrusion zones. Figures 8(a) and 8(d) show more warping deformation all over the three zones and under the full range of nozzle temperatures. Figures 8(b) and 8(c) meanwhile show more and less warping deformation. The fluctuation of warping for both pure PLA and advanced PLA+ over the independent nozzle temperature was non-uniform as shown in Figures 8(a), 8(c) and 8(d) while it shows itself only consistent at two zones (normal extrusion and over extrusion) as shown in Figure 8(b). Likewise, the best print quality for pure PLA was at $230^{\circ} \mathrm{C}$ nozzle temperature with the mean and standard deviation of $3.212 \pm 0.070 \mathrm{~mm}(0.375 \%$ overall error and
$99.625 \%$ overall accuracy). In contrast, the best print quality for advanced PLA + was at $250^{\circ} \mathrm{C}$ nozzle temperature and $\pm 45^{\circ}$ infill line direction with the mean and standard deviation of $3.223 \pm 0.135 \mathrm{~mm}(0.719 \%$ overall error and $99.281 \%$ overall accuracy). Both thermoplastic filament materials show best print quality over extrusion range with $\pm 45^{\circ}$ infill line direction. As expected, the pure PLA at $90^{\circ}$ infill line direction $\left(210^{\circ} \mathrm{C}\right.$ and $\left.230^{\circ} \mathrm{C}\right)$ and at $45^{\circ}$ infill line direction $\left(210^{\circ} \mathrm{C}\right)$ and advanced PLA + at $90^{\circ}$ infill line direction $\left(205^{\circ} \mathrm{C}\right.$ and $210^{\circ} \mathrm{C}$ ) show high warping deformation which allows the thermoplastic filament materials to shrink. At this extrusion range, the printed sample could not reach the true value of the original CAD file which is $3.2 \mathrm{~mm}$ due to long internal stresses and long distance to cool down, while other infill line directions reach near-zero warping.

In general, under extrusion leads to shrinking very quickly at the first layer before starting the second layer. Over extrusion leads to taking more time to cool down and more material fall during printing layers but still can print. Normal extrusion range represents an excellent quality print. To avoid warping, the nozzle temperature needs to be high enough to ensure good lamination between each layer. Pure PLA and advanced PLA+ showed a high degree of warping deformation during the cooling process (due to its semi-crystalline nature), which led to distortion and decoupling from the printer's bed. Furthermore, inhomogeneity also occurs within the layers. This leads to free-edge warping, which, in turn, induces positive inter-laminar and shear stresses, pulling the layers apart. Additionally, both thermoplastic filament materials have a lower coefficient of thermal expansion, which reduced the effect of warping deformation but did not adhere to the printed surface large parts cracking as they are printed. With all of this in mind, it is easy to understand why a great many FDM 3D printer manufacturers are producing and supporting FDM 3D printers that print exclusively using pure PLA and advanced PLA+.
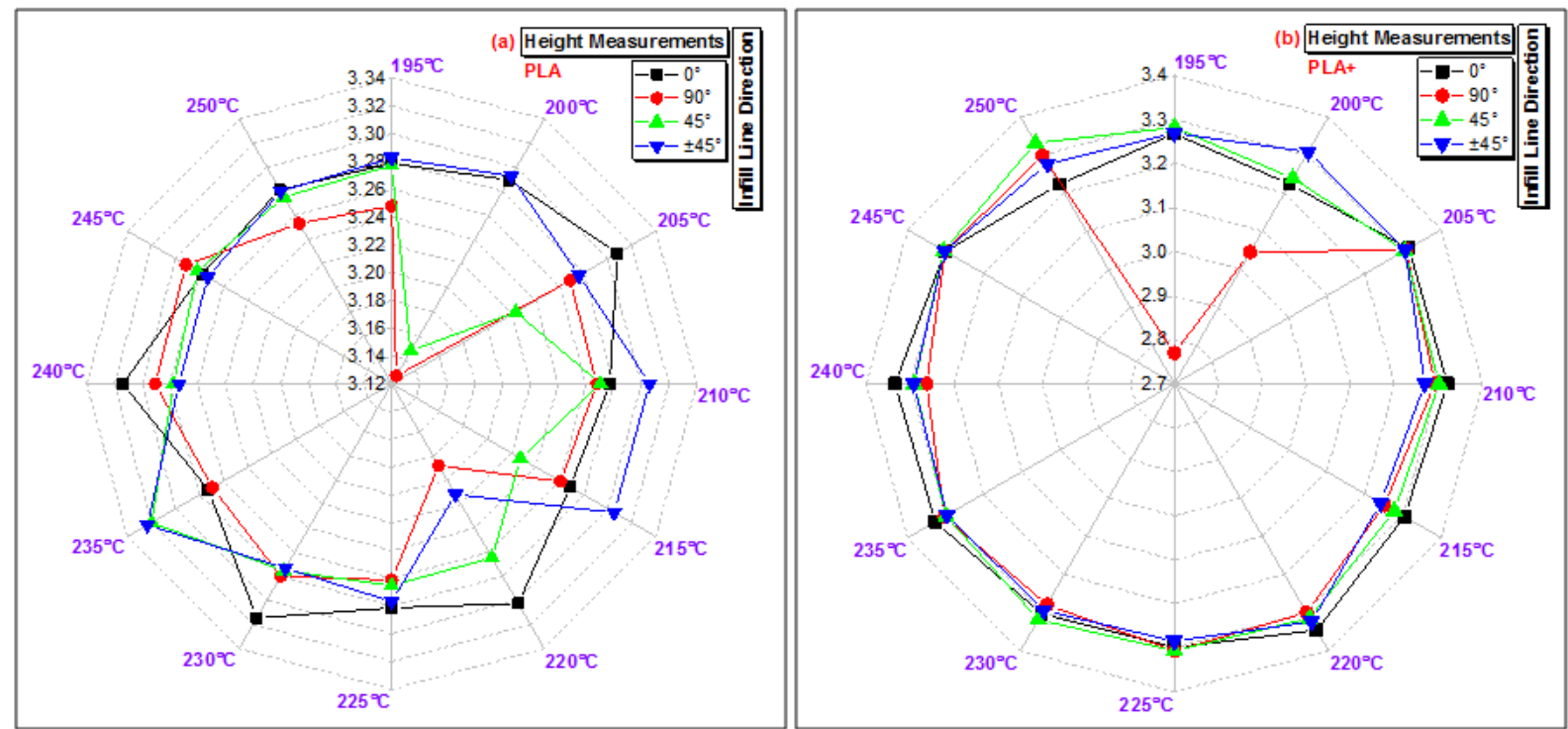

Figure 7. The height measurements (warping deformation analysis) for both (a) pure PLA and (b) advanced PLA+ without adding epoxy resin adhesive on the platform (print bed) 

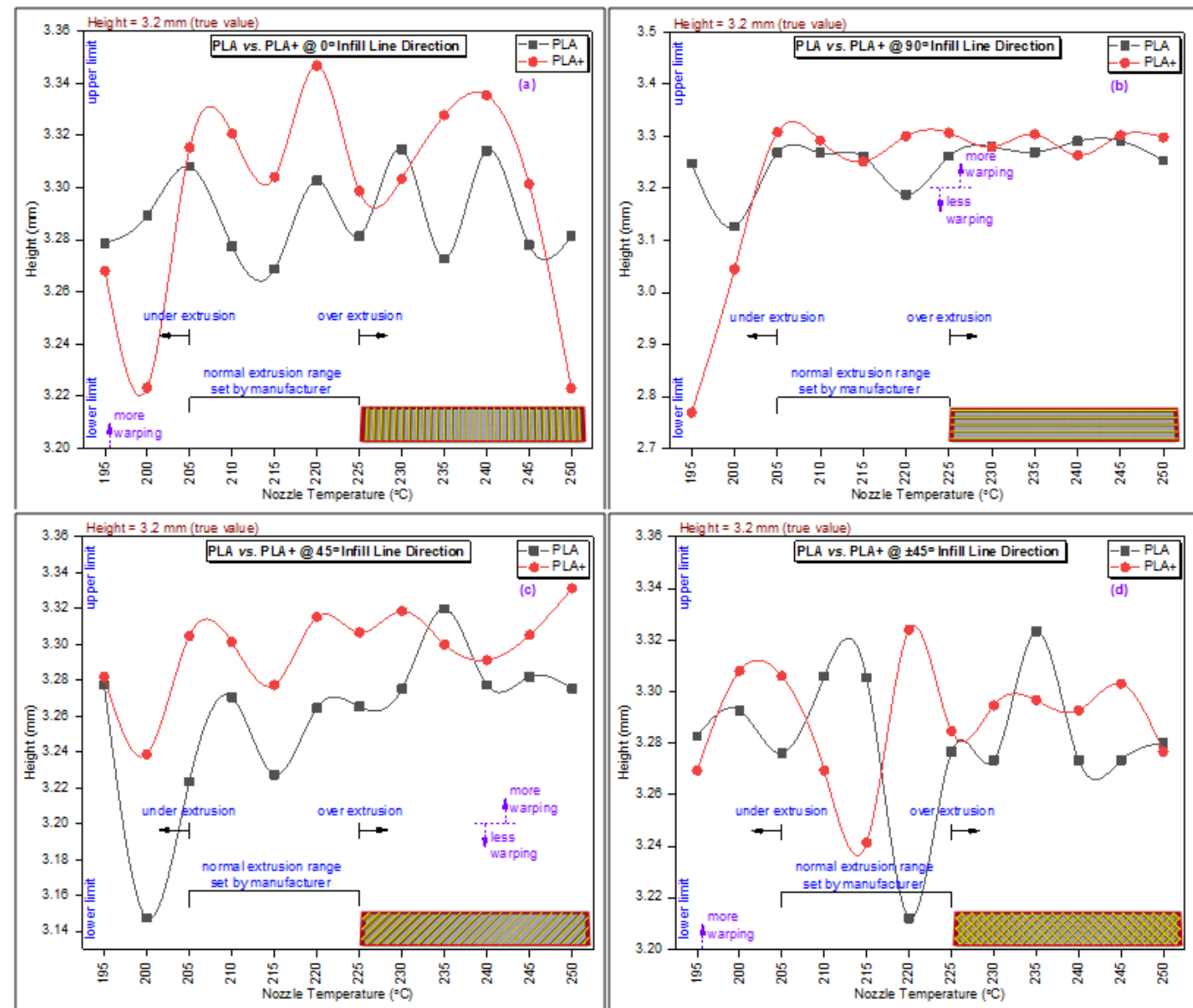

Figure 8. The height measurements (warping deformation analysis) for both pure PLA and advanced PLA + at (a) $0^{\circ}$, (b) $90^{\circ}$, (c) $45^{\circ}$ and (d) $\pm 45^{\circ}$ infill line direction
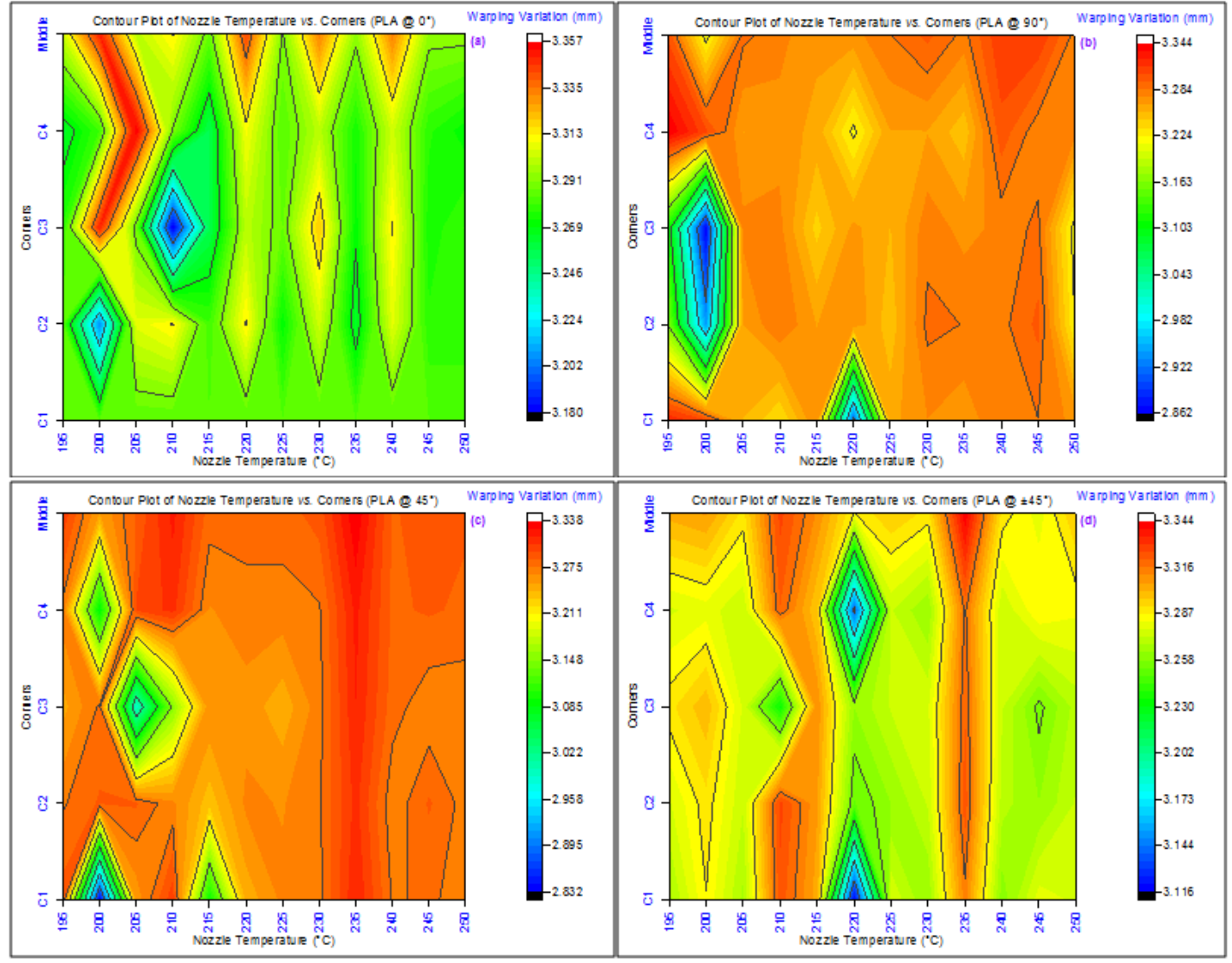

Figure 9. Contour plot of corner 1, 2, 3, 4 including the middle corresponded to the nozzle temperature without thermos adhesive at $20 \%$ infill density and infill line direction of (a) PLA@ $00^{\circ}$ (b) PLA@90 (c) PLA@45 and (d) PLA@ @45 

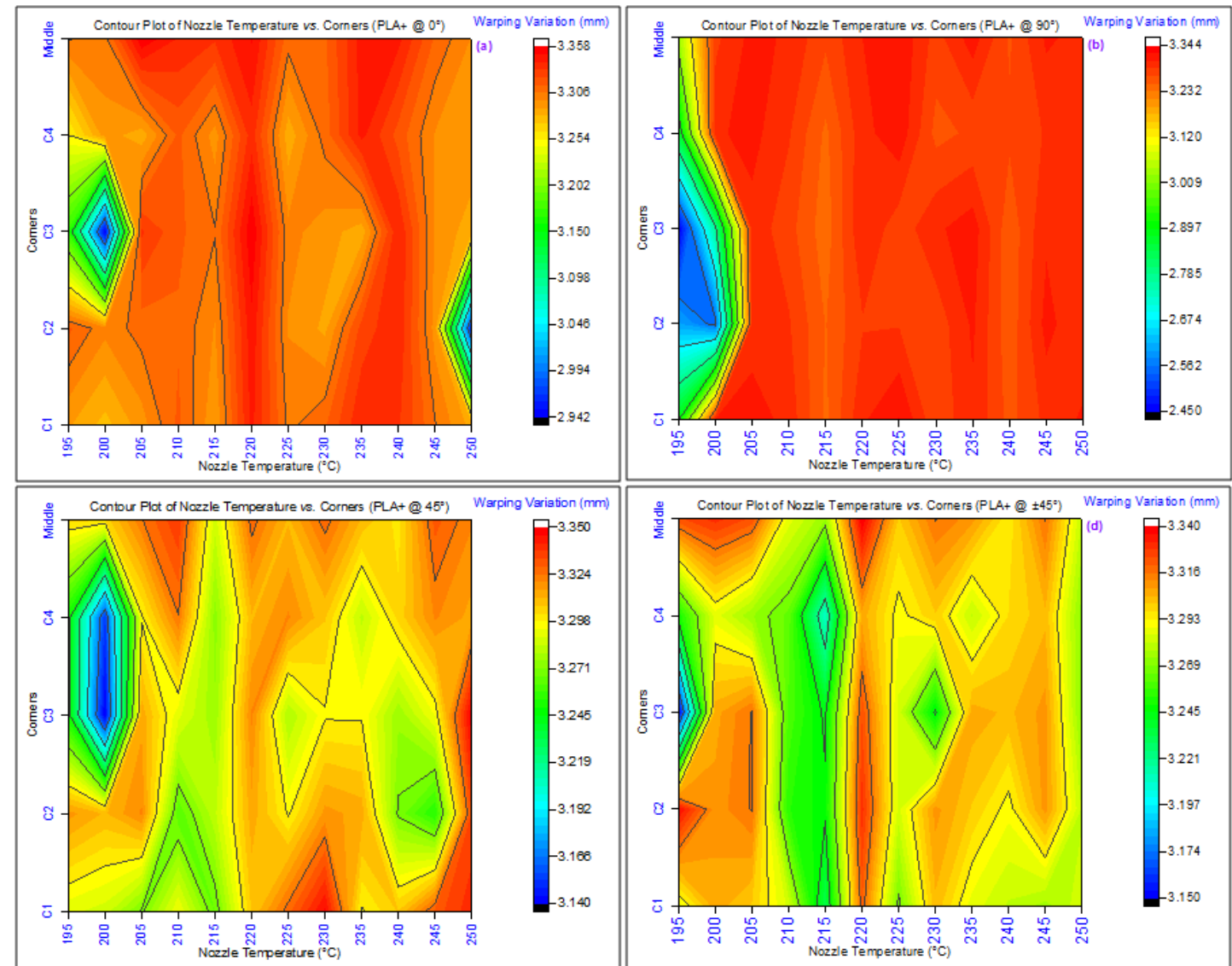

Figure 10. Contour plot of corner 1, 2, 3, 4 including the middle corresponded to the nozzle temperature without thermos adhesive at $20 \%$ infill density and infill line direction of (a) PLA+@0 (b) PLA+@90 (c) PLA+@45 and (d) PLA+@ $\pm 45^{\circ}$

Figure 9 and Figure 10 show the contour plot of all corners $(\mathrm{C} 1, \mathrm{C} 2, \mathrm{C} 3, \mathrm{C} 4)$ including the middle which responds to the independent variable nozzle temperature. The interval of the nozzle temperatures started from $195^{\circ} \mathrm{C}$ and was successively increased by $5^{\circ} \mathrm{C}$ up to $250^{\circ} \mathrm{C}$. This shows that the best result of minimum warping deformation value happens at all corners $(\mathrm{C} 1, \mathrm{C} 2, \mathrm{C} 3, \mathrm{C} 4)$ including the middle without using thermos adhesive in order to study the warping effect. Dark blue indicating that the corner could not reach the true value of the original STL file - which is more likely to be - appears under the extrusion zone. The data obtained from Figure 9 and Figure 10 are consistent and coherent with what was found in Figure 8. Warping deformation is not, however, an exclusive drawback of AM as it must also be taken into account when components are produced by many other manufacturing techniques, such as casting or welding. So, optimizing nozzle temperature or, as will be seen in the following section, optimizing the printing speed can partially avoid this issue. Suitable nozzle temperature can guarantee a sufficient time of heating the thermoplastic filament materials. If the nozzle temperature is too low (under extrusion), the thermoplastic filament material has not melted completely, which leads to plug nozzle because of the larger viscosity. If the nozzle temperature is too high, crosslinking reaction will occur, and thermoplastic filament materials may even burn. In conclusion, it is clearly shown that concerning extrusion, the dimensional accuracy follows the non-linear relation. The actual amount of warping can differ between the corners. This can, in any degree, be attributed to the fact that the printing surface is never perfectly even. Consequently, some parts of the first layer adhere much better to the printing bed than others, leading to a decreased amount of warping/shrinking.

\subsection{Performance Analysis of Dimensional Accuracy (DA)}

The accuracy of FDM 3D printed parts becomes much more vital when the printed parts need to be assembled for mandatory functionality. These mechanical parts must have high dimensional accuracies in order not to have loose connections between the connecting FDM 3D printed parts. Corresponding dimensions may have clearance, transition and interference fit tolerances which are standardized by ISO System of Limits and Fits depending on the function of the assembly [28]. The measurements of dimensional variability provided a gauge of both the quality of the build (lattice failure rates, warping) and consistency between builds via the comparison of multiple identical copies. In the second phase of the experimentations, the specimens were subjected to studying the dimensional accuracy at width and length and the average was considered. So, in order to acquire adequate printing conditions, 96 printed samples were produced varying the nozzle temperature. Both types of test specimens were subjected to a dimensional evaluation. The dimensional accuracy study was statistically conducted regarding deviations from the true value of the 
original STL file of each of the main dimensions. Additionally, deposited cross-sections of filaments extruded at different temperatures were analyzed to establish the correlation between dimensional deviation and working temperature range. Figure 11 shows the CAD file of the printed part for dimensional accuracy analysis of the actual values of $63.50 \mathrm{~mm}(\mathrm{~L})$ and $9.53 \mathrm{~mm}(\mathrm{~W})$. Geometrical accuracy can be measured using a digital laser measure PLR 50 C (purchased from Rober BOSCH, Germany) and calculation of the deviation relative to the original STL file format. The minimum deviation between the fabricated part dimension and CAD model dimension was selected as part of the accuracy criteria to measure the deviation.

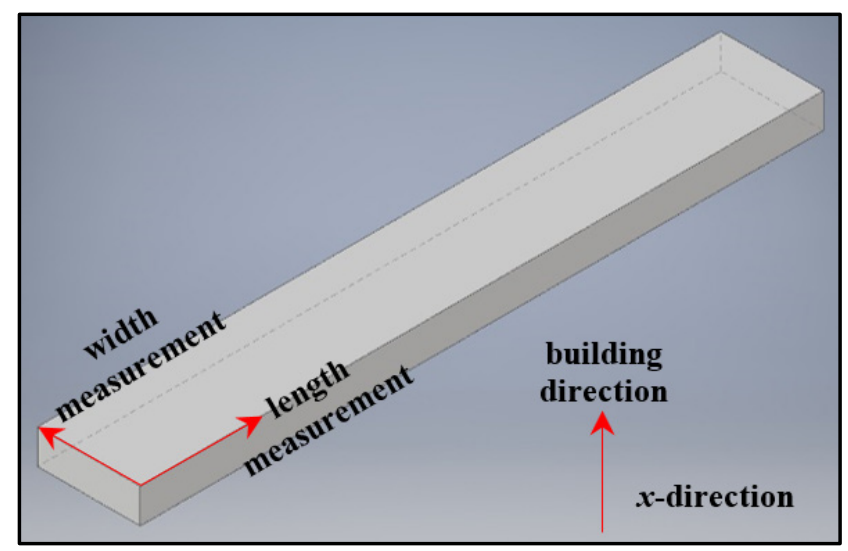

Figure 11. CAD file of the printed part target for dimensional accuracy analysis

For pure PLA as shown in Figure 12(a), the mean and standard deviation of the length measurements were $63.436 \mathrm{~mm}$ (for $0^{\circ}$ ), $63.436 \mathrm{~mm}$ (for $90^{\circ}$ ), $63.436 \mathrm{~mm}$ (for $45^{\circ}$ ) and $63.436 \mathrm{~mm}$ (for $\pm 45^{\circ}$ ) with $\pm 0.000 \mathrm{~mm}$ standard deviation for all infill line directions. The minimum and maximum mean height measurements were $63.436 \mathrm{~mm}$ and $63.437 \mathrm{~mm}$ (for $0^{\circ}$ ), $63.436 \mathrm{~mm}$ and $63.437 \mathrm{~mm}$ (for $90^{\circ}$ ), $63.435 \mathrm{~mm}$ and $63.437 \mathrm{~mm}$ (for $45^{\circ}$ ) and $63.436 \mathrm{~mm}$ and $63.437 \mathrm{~mm}$ (for $\pm 45^{\circ}$ ), respectively. The minimum and maximum $( \pm \mathrm{SD})$ for all infill line directions were $\pm 0.000 \mathrm{~mm}$ and $\pm 0.001 \mathrm{~mm}$, respectively. This indicates a consistently high degree of precision and a highly accurate measuring system with $99.900 \%$ (for $0^{\circ}$ and $90^{\circ}$ ) and $99.899 \%$ (for $45^{\circ}$ and $\pm 45^{\circ}$ ), providing a level of confidence and the total coverage factor of $k=3$ as overall and with minimum and maximum percentage of $99.899 \%$ and $99.900 \%$ (for $0^{\circ}$ and $90^{\circ}$ ) and $99.898 \%$ and $99.901 \%$ (for $45^{\circ}$ and $\pm 45^{\circ}$ ), respectively. All systematic errors (caused by incorrect calibration of the measuring instrument) were almost eliminated and only random errors (caused by the accuracy limit of the measuring instrument) were calculated by $0.100 \%$ (for $0^{\circ}$ and $90^{\circ}$ ) and $0.101 \%$ (for $45^{\circ}$ and $\pm 45^{\circ}$ ) with minimum and maximum percentage of $0.100 \%$ and $0.101 \%$ (for $0^{\circ}, 90^{\circ}$ and $\pm 45^{\circ}$ ), and $0.099 \%$ and $0.102 \%$ (for $45^{\circ}$ ), respectively, under different nozzle temperature.

For advanced PLA+ as shown in Figure 12(b), the mean and $( \pm \mathrm{SD})$ of the length measurements were consistent and identical in all infill line directions by almost $63.436 \pm 0.000 \mathrm{~mm}$ with minimum and maximum mean height measurements of $63.436 \pm 0.000 \mathrm{~mm}$ and $63.438 \pm 0.001 \mathrm{~mm}$ (for $0^{\circ}$ and $90^{\circ}$ ) and $63.436 \pm 0.000 \mathrm{~mm}$ and $63.437 \pm 0.001 \mathrm{~mm}$ (for $45^{\circ}$ ) and $63.436 \pm 0.000 \mathrm{~mm}$ and $63.436 \pm 0.001 \mathrm{~mm}$ (for $\pm 45^{\circ}$ ), respectively. This indicates a consistently high degree of precision and a highly accurate measuring system with $99.900 \%$ (for $0^{\circ}$ and $90^{\circ}$ ) and $99.899 \%$ (for $45^{\circ}$ and $\pm 45^{\circ}$ ), provoding a level of confidence and the total coverage factor of $k=3$ as overall and with minimum and maximum percentages of $99.899 \%$ and $99.902 \%$ (for $0^{\circ}$ and $90^{\circ}$ ), $99.899 \%$ and $99.901 \%$ (for $45^{\circ}$ ) and $99.899 \%$ and $99.900 \%$ (for $\pm 45^{\circ}$ ), respectively. All systematic errors (caused by incorrect calibration of the measuring instrument) were almost eliminated and only random errors (caused by the accuracy limit of the measuring instrument) were calculated by $0.100 \%$ (for $0^{\circ}$ and $90^{\circ}$ ) and $0.101 \%$ (for $45^{\circ}$ and $\pm 45^{\circ}$ ) with minimum and maximum percentages of $0.098 \%$ and $0.101 \%$ (for $0^{\circ}$ and $90^{\circ}$ ), $0.099 \%$ and $0.101 \%$ (for $45^{\circ}$ ) and $0.100 \%$ and $0.101 \%$ (for $\pm 45^{\circ}$ ), respectively, under different nozzle temperature.

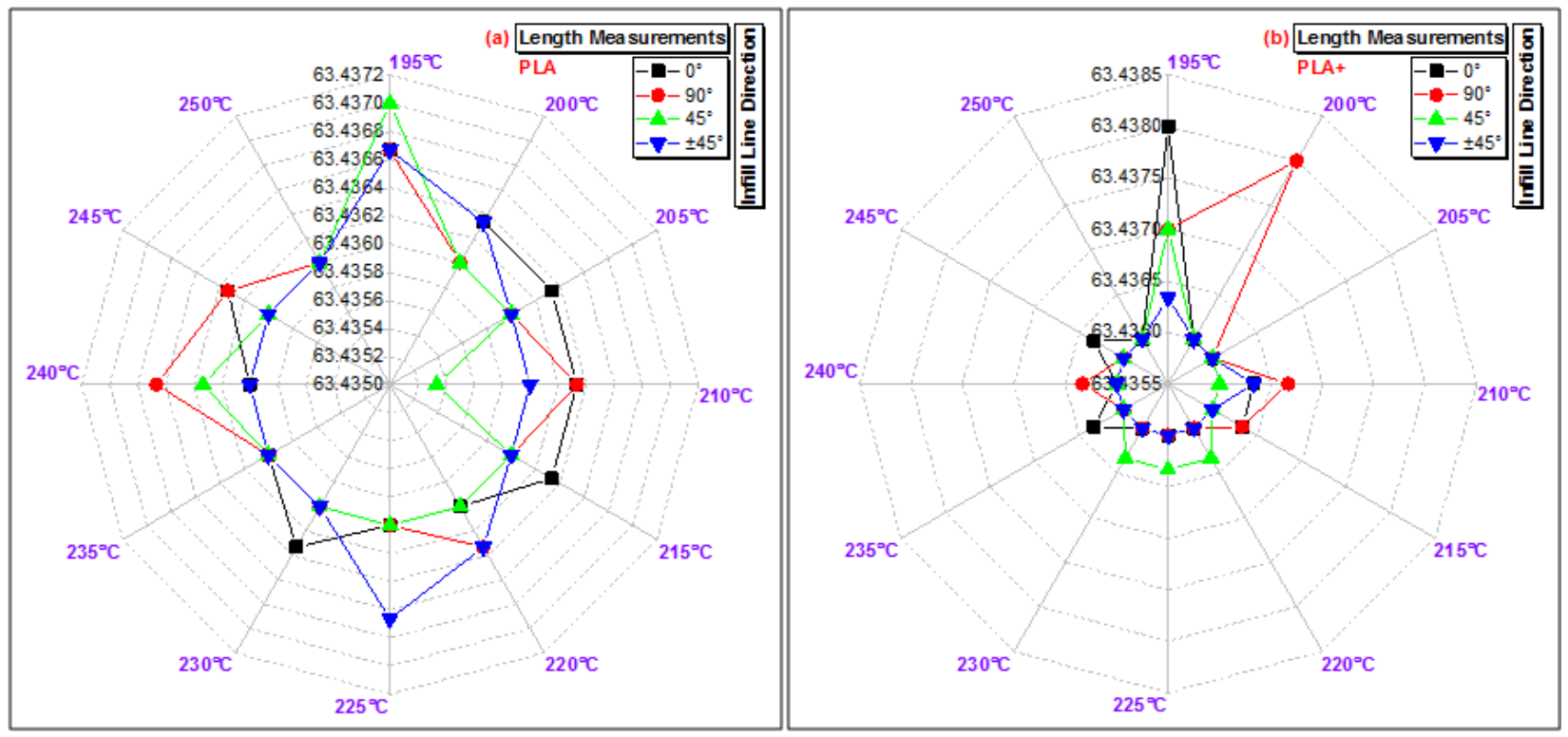

Figure 12. Length measurements geometry variation for (a) pure PLA and (b) advanced PLA+ 
In general, it is observed that deviation from the ideal dimension (STL file) was encountered on the first layer filament material deposition due to the filament material adhesion problems which affected the increase in the length of other layers of the 3D rectangular object. Under extrusion zone low dimensional accuracy is shown (especially at $0^{\circ}, 90^{\circ}, 45^{\circ}$ infill line direction) compared with other zones.

Figure 13 shows the performance of pure PLA versus advanced PLA + at $0^{\circ}, 90^{\circ}, 45^{\circ}$ and $\pm 45^{\circ}$ infill line direction with $20 \%$ infill density. Three different zones were examined namely under extrusion, normal extrusion and over extrusion zones. As can be seen, under extrusion represents the highest variation in length measurements compared to the true value of $63.5 \mathrm{~mm}$ in the original STL file both pure PLA and advanced PLA + at all infill line directions. Then, the performance of both thermoplastic materials starts to fluctuate up and down with the boundary line of $63.5 \mathrm{~mm}$ with a $99.9 \%$, providing a level of confidence. Moreover, advanced PLA + shows more stable from $215^{\circ} \mathrm{C}$ to $250^{\circ} \mathrm{C}$ nozzle temperature at $\pm 45^{\circ}$ infill line direction due to the fact that the internal structure leads to rigidity in the final printed shape.

It can be concluded that there is deformation towards the bottom layer of all FDM 3D printed parts. The variation can be the effect of warping during the fabrication of the FDM 3D printed parts when the thermoplastic filament materials are being heated up and extruded through the heated nozzle near to the point of fusion. The thermoplastic filament material deposited is in the form of a semi-molten state. During the material deposition, the nozzle is cooled down from the glass transition temperature to around ambient temperature, this will cause internal stress that develops into warping deformation around the corners. Finally, it will affect the properties of the printed samples, resulting in a weak interlayer bonding and a high porosity. Besides, having a large base area at small-size printed parts increases the chances for warping (deformation induced by residual thermal stresses) of the material with the higher value and finally affects the length accuracy of the printed parts.

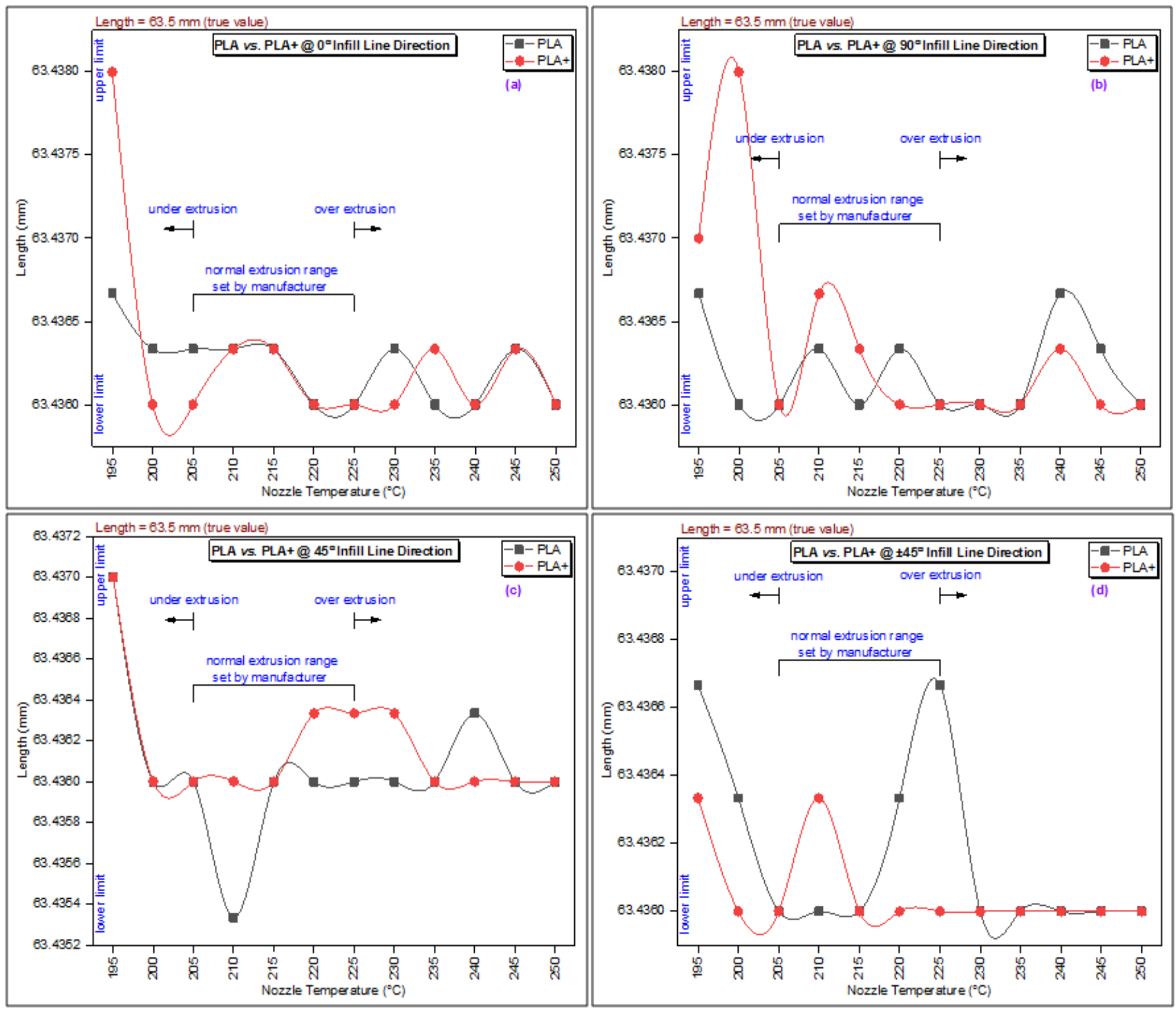

Figure 13. The length measurements (warping deformation analysis) for both pure PLA and advanced PLA+ at (a) $0^{\circ}$, (b) $90^{\circ}$, (c) $45^{\circ}$ and (d) $\pm 45^{\circ}$ infill line direction 


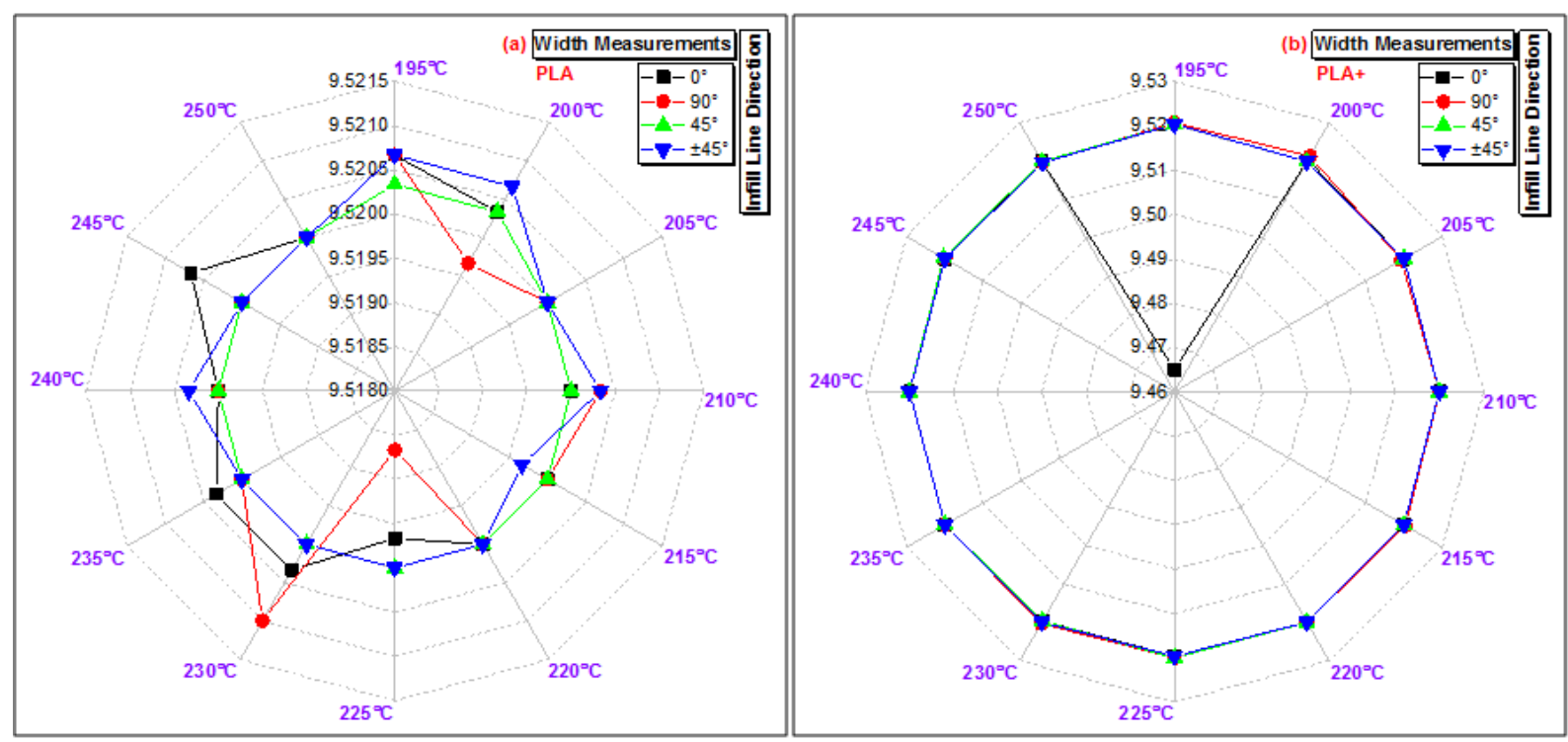

Figure 14. Width measurements geometry variation for (a) pure PLA and (b) advanced PLA+

For pure PLA as shown in Figure 14(a), the mean and standard deviation (mean $\pm \mathrm{SD}$ ) of the width measurements were $9.520 \pm 0.000 \mathrm{~mm}$ for all infill line directions with minimum and maximum mean width measurements of $9.520 \pm 0.000 \mathrm{~mm}$ and $9.521 \pm 0.001 \mathrm{~mm}$ (for $0^{\circ}$ and $\pm 45^{\circ}$ ), $9.519 \pm 0.000 \mathrm{~mm}$ and $9.521 \pm 0.001 \mathrm{~mm}$ (for $90^{\circ}$ ) and $9.520 \pm 0.000 \mathrm{~mm}$ and $9.520 \pm 0.001 \mathrm{~mm}$ (for $45^{\circ}$ ), respectively. This indicates a consistently high degree of precision and a highly accurate measuring system with 99.897\% (for $0^{\circ}$ ), 99.895\% (for $90^{\circ}$ ), $99.896 \%$ (for $45^{\circ}$ ) and $99.902 \%$ (for $\pm 45^{\circ}$ ), providing a level of confidence and the total coverage factor of $k=3$ as overall and with minimum and maximum percentages of $99.892 \%$ and 99.902\% (for $0^{\circ}$ and $\pm 45^{\circ}$ ), $99.881 \%$ and $99.906 \%$ (for $90^{\circ}$ ) and $99.895 \%$ and $99.899 \%$ (for $45^{\circ}$ ), respectively. All systematic errors (caused by incorrect calibration of the measuring instrument) were almost eliminated and only random errors (caused by the accuracy limit of the measuring instrument) were calculated by $0.103 \%$ (for $0^{\circ}$ and $\pm 45^{\circ}$ ), $0.105 \%$ (for $90^{\circ}$ ) and $0.104 \%$ (for $45^{\circ}$ ) with minimum and maximum percentages of $0.098 \%$ and $0.108 \%$ (for $0^{\circ}$ and $\pm 45^{\circ}$ ), $0.094 \%$ and $0.119 \%$ (for $90^{\circ}$ ) and $0.101 \%$ and $0.105 \%$ (for $45^{\circ}$ ), respectively, under different nozzle temperature.

For advanced PLA+ as shown in Figure 14(b), the mean and standard deviation of the width measurements were $9.515 \pm 0.001 \mathrm{~mm}$ (for $0^{\circ}$ ) and $9.520 \pm 0.000 \mathrm{~mm}$ (for $90^{\circ}, 45^{\circ}$ and $\pm 45^{\circ}$ ) with minimum and maximum mean width measurements of $9.465 \pm 0.000 \mathrm{~mm}$ and $9.520 \pm 0.004$ $\mathrm{mm}$ (for $0^{\circ}$ ), $9.519 \pm 0.000 \mathrm{~mm}$ and $9.521 \pm 0.001 \mathrm{~mm}$ (for $90^{\circ}$ ) and $9.520 \pm 0.000 \mathrm{~mm}$ and $9.520 \pm 0.001 \mathrm{~mm}$ (for $45^{\circ}$ and $\pm 45^{\circ}$ ), respectively. This indicates a consistently high degree of precision and a highly accurate measuring system with $99.847 \%$ (for $0^{\circ}$ ), $99.897 \%$ (for $90^{\circ}$ ) and $99.895 \%$ (for $45^{\circ}$ and $\pm 45^{\circ}$ ), providing a level of confidence and the total coverage factor of $k=3$ as overall and with minimum and maximum percentages of $99.318 \%$ and $99.899 \%$ (for $0^{\circ}$ ), $99.888 \%$ and $99.909 \%$ (for $90^{\circ}$ ) and $99.892 \%$ and $99.899 \%$ (for $45^{\circ}$ and $\pm 45^{\circ}$ ), respectively. All systematic errors (caused by incorrect calibration of the measuring instrument) were almost eliminated and only random errors (caused by the accuracy limit of the measuring instrument) were calculated by $0.153 \%$ (for $0^{\circ}$ ), $0.103 \%$ (for $90^{\circ}$ ) and $0.105 \%$ (for $45^{\circ}$ and $\pm 45^{\circ}$ ) with minimum and maximum percentage of $0.101 \%$ and $0.682 \%$ (for $0^{\circ}$ ), $0.091 \%$ and $0.112 \%$ (for $90^{\circ}$ ) and $0.101 \%$ and $0.108 \%$ (for ${ }^{\circ}$ and $\pm 45^{\circ}$ ), respectively, under different nozzle temperatures. This information is signwhen designing and manufacturing various parts with precise thin sections, high-aspect ratios or close-fitting dimensional tolerance/accuracy.

Width measurements for advanced PLA+ was more stable and coherent than pure PLA. The $45^{\circ}$ and $\pm 45^{\circ}$ infill line directions show the best print quality results for advanced PLA+ under all zones.

Figure 15 shows the performance of pure PLA versus advanced PLA + at $0^{\circ}, 90^{\circ}, 45^{\circ}$ and $\pm 45^{\circ}$ infill line direction with $20 \%$ infill density. Three different zones were examined namely under extrusion, normal extrusion and over extrusion zones. As can be seen, under extrusion represents the highest variation in width measurements compared to the true value of $9.53 \mathrm{~mm}$ in the original STL file for both pure PLA and advanced PLA + at all infill line directions. Then, the performance of both thermoplastic materials starts to fluctuate up and down with the boundary line of $63.5 \mathrm{~mm}$ with a $99.8 \%$, providing a level of confidence. Moreover, both filament materials show themselves to be more stable (around almost $\sim 9.52 \mathrm{~mm}$ ) from $205^{\circ} \mathrm{C}$ to $250^{\circ} \mathrm{C}$ nozzle temperature at $\pm 0^{\circ}$ infill line direction while others show otherwise. With all of these many issues, the dimensional deviations permanently have a slight amount of dispersion which is easily solved by redesigning the FDM 3D printed samples by beginning with a mathematical modeling relationship of the results, or by undergoing finishing process parameters. Nevertheless, the mechanical properties do not show themselves to be equally important to such relative advantage. It clearly shows that the width variation, for advanced PLA+, remains almost constant with the line width compensation while decreases with an increase in the value of nozzle temperature at $90^{\circ}$ infill line direction. Similar to dimensional error, the width variation follows the non-linear relation concerning nozzle temperature at $90^{\circ}$ infill line direction. 

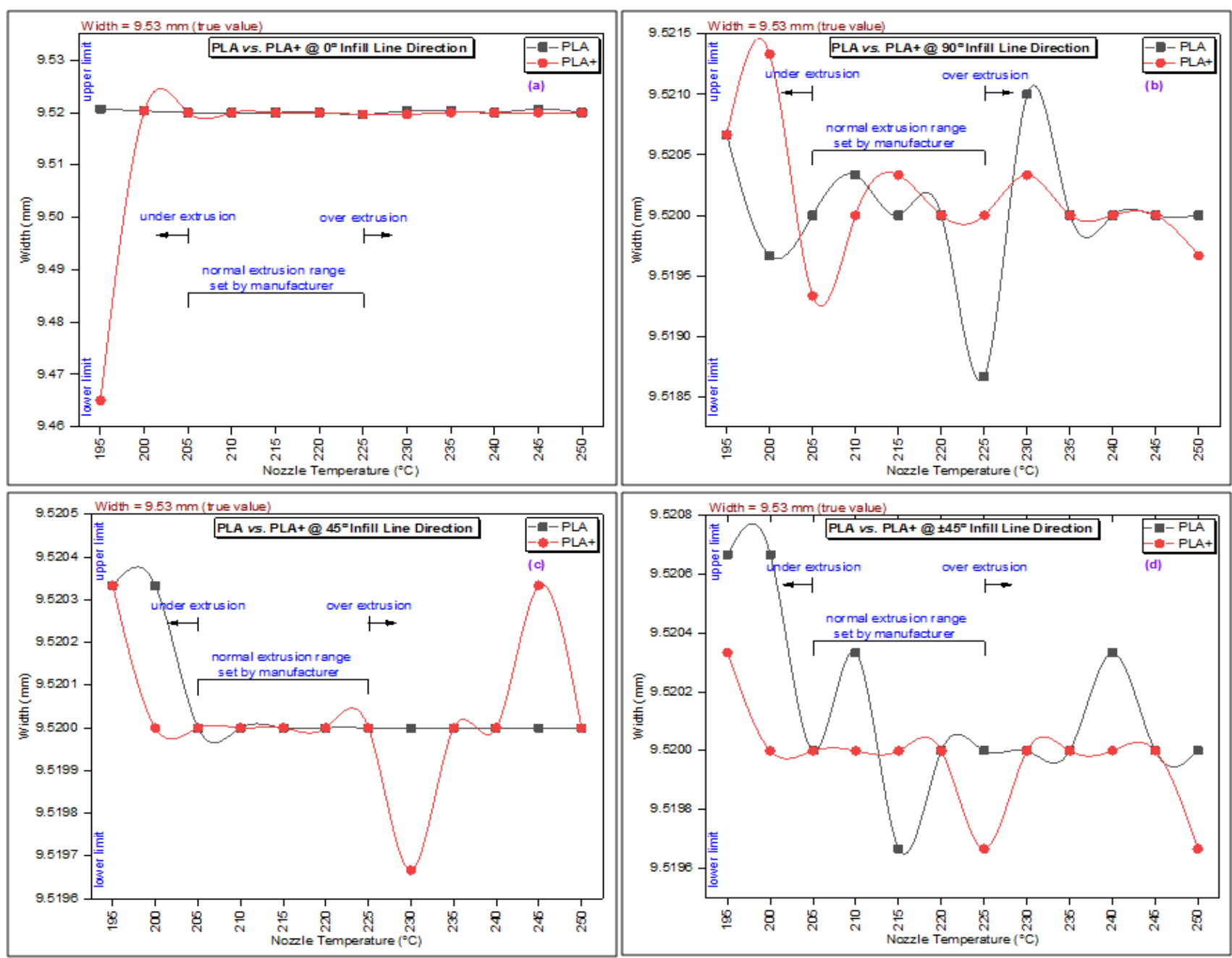

Figure 15. The width measurements (warping deformation analysis) for both pure PLA and advanced PLA + at (a) $0^{\circ}$, (b) $90^{\circ}$, (c) $45^{\circ}$ and (d) $\pm 45^{\circ}$ infill line direction

\subsection{Performance Analysis of Density}

In the last experiment phase, the nozzle temperature was varying from $195^{\circ} \mathrm{C}$ to $250^{\circ} \mathrm{C}$ with the increments of $5^{\circ} \mathrm{C}$ with $0^{\circ}, 90^{\circ}, 45^{\circ}, \pm 45^{\circ}$ infill line direction. Other process parameter values remain constant as presented in Table 1. The density of the thermoplastic filament material is directly measured experimentally using weight divided by the volume of a filament segment. The size of voids (volume) was quantified as $1.553 \mathrm{~cm}^{3}$ in all printed samples with infill line direction of $0^{\circ}, 90,45^{\circ}$ and $\pm 45^{\circ}$. So, the ideal volume of the rectangular solid is $1.94 \mathrm{~cm}^{3}$ with $100 \%$ infill density. However, with $20 \%$ infill density, the ideal volume of the rectangular shape is 0.387 $\mathrm{cm}^{3}$. Bear in mind that the FDM 3D process generates void spaces between material deposition lines, resulting in lower properties, limiting, even more, the applicability of printed components. Also, in reality, an infill density of $20 \%$ does not necessarily imply that the part is $20 \%$ solid due to, for example, air gap and other process parameters during construction. This is because, by modifying only the extrusion nozzle temperature, the deposited section changes not only the dimensional accuracy of the printed parts but also causes air between layers, resulting in bubbles.

Figure 16 shows the relationship between each nozzle temperature and its corresponding filament's density. It can be seen that as shown in Figure 13, the density measurements of both filaments at $90^{\circ}$ infill line direction have higher values compared with other infill line directions $\left(0^{\circ}, 45^{\circ}, \pm 45^{\circ}\right)$. The $0^{\circ}$ infill line direction shows the lower value of density over the specific range of nozzle temperatures. The $45^{\circ}$ and $\pm 45^{\circ}$ fluctuated up and down just above the $0^{\circ}$ and down far away from $90^{\circ}$. Still, under extrusion zone, the density of the filament has a slight increase and then decreases in the other two ranges (normal extrusion and over extrusion). This is due to the fact that extrusion of the filament under extrusion becomes hard and can barely collect continuous filament with uniform diameters. This is caused by high viscosity and low fluidity at a temperature below its melting temperature. On the other hand, the density of both filaments at $0^{\circ}, 45^{\circ}, \pm 45^{\circ}$ is low in general and there is small deviation, especially for advanced PLA+.

For pure PLA as shown in Figure 16(a), the (mean \pm SD) of the density was $1.728 \pm 0.017 \mathrm{~g} / \mathrm{cm}^{3}$ (for $0^{\circ}$ ), $1.891 \pm 0.015 \mathrm{~g} / \mathrm{cm}^{3}$ (for $90^{\circ}$ ), $1.758 \pm 0.024 \mathrm{~g} / \mathrm{cm}^{3}$ (for $45^{\circ}$ ) and $1.749 \pm 0.018 \mathrm{~g} / \mathrm{cm}^{3}$ (for $\pm 45^{\circ}$ ), respectively. Furthermore, the minimum and maximum values of the density was $1.699 \mathrm{~g} / \mathrm{cm}^{3}$ and $1.748 \mathrm{~g} / \mathrm{cm}^{3}$ (for $0^{\circ}$ infill line direction and $205^{\circ} \mathrm{C}$ and $245^{\circ} \mathrm{C}$ nozzle temperature), 1.874 $\mathrm{g} / \mathrm{cm}^{3}$ and $1.924 \mathrm{~g} / \mathrm{cm}^{3}$ (for $90^{\circ}$ infill line direction and $200^{\circ} \mathrm{C}$ and $230^{\circ} \mathrm{C}$ nozzle temperature), $1.712 \mathrm{~g} / \mathrm{cm}^{3}$ and 
$1.805 \mathrm{~g} / \mathrm{cm}^{3}$ (for $45^{\circ}$ infill line direction and $195^{\circ} \mathrm{C}$ and $200^{\circ} \mathrm{C}$ nozzle temperature) and $1.715 \mathrm{~g} / \mathrm{cm}^{3}$ and 1.787 $\mathrm{g} / \mathrm{cm}^{3}$ (for $\pm 45^{\circ}$ infill line direction and $195^{\circ} \mathrm{C}$ and $220^{\circ} \mathrm{C}$ nozzle temperature).

For advanced PLA+ as shown in Figure 16(b), the (mean $\pm \mathrm{SD}$ ) of the density was $1.610 \pm 0.013 \mathrm{~g} / \mathrm{cm}^{3}$ (for $0^{\circ}$ ), $1.793 \pm 0.118 \mathrm{~g} / \mathrm{cm}^{3}$ (for $90^{\circ}$ ), $1.637 \pm 0.022 \mathrm{~g} / \mathrm{cm}^{3}$ (for $45^{\circ}$ ) and $1.629 \pm 0.018 \mathrm{~g} / \mathrm{cm}^{3}$ (for $\pm 45^{\circ}$ ), respectively. Furthermore, the minimum and maximum values of the density were $1.590 \mathrm{~g} / \mathrm{cm}^{3}$ and $1.633 \mathrm{~g} / \mathrm{cm}^{3}$ (for $0^{\circ}$ infill line direction and $230^{\circ} \mathrm{C}$ and $250^{\circ} \mathrm{C}$ nozzle temperature), $1.720 \mathrm{~g} / \mathrm{cm}^{3}$ and $2.112 \mathrm{~g} / \mathrm{cm}^{3}$ (for $90^{\circ}$ infill line direction and $195^{\circ} \mathrm{C}$ and $235^{\circ} \mathrm{C}$ nozzle temperature), $1.609 \mathrm{~g} / \mathrm{cm}^{3}$ and $1.680 \mathrm{~g} / \mathrm{cm}^{3}$ (for $45^{\circ}$ infill line direction and $225^{\circ} \mathrm{C}$ and $250^{\circ} \mathrm{C}$ nozzle temperature) and $1.601 \mathrm{~g} / \mathrm{cm}^{3}$ and $1.664 \mathrm{~g} / \mathrm{cm}^{3}$ (for $\pm 45^{\circ}$ infill line direction and $215^{\circ} \mathrm{C}$ and $235^{\circ} \mathrm{C}$ nozzle temperature).
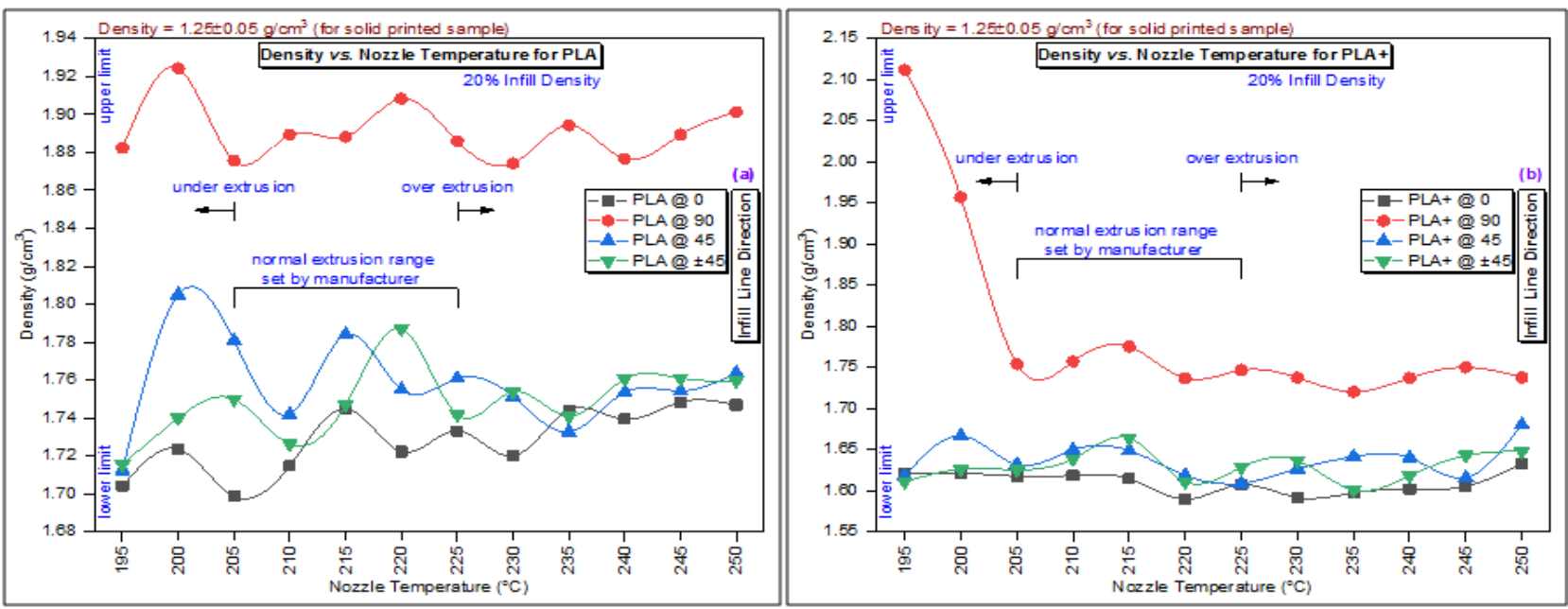

Figure 16. Filament density versus nozzle temperature relationship for both (a) pure PLA and (b) advanced PLA + at $0^{\circ}, 90^{\circ}, 45^{\circ}$ and $\pm 45^{\circ}$ infill line direction
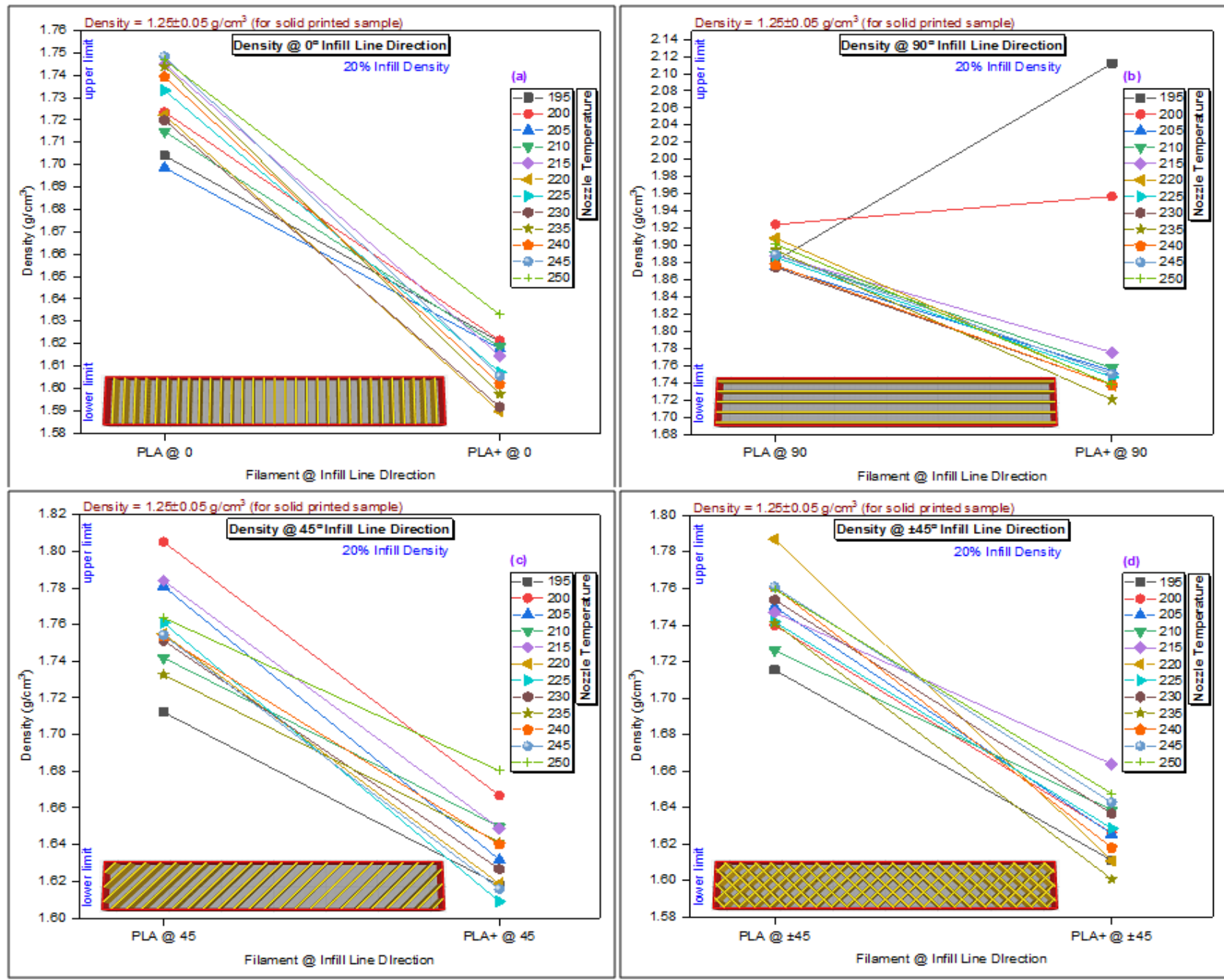

Figure 17. Twelve-level density experiment for both pure PLA and advanced PLA + at (a) $0^{\circ}$, (b) $90^{\circ}$, (c) $45^{\circ}$ and (d) $\pm 45^{\circ}$ infill line direction 
Figure 17 shows the influence of the infill line direction on the density of the printed samples at different nozzle temperatures. It can be seen clearly that all advanced PLA + printed parts densities decreased by $6.850 \%$ (for $0^{\circ}$ ), $5.149 \%$ (for $90^{\circ}$ ), $6.865 \%$ (for $45^{\circ}$ ) and $6.825 \%$ (for $\pm 45^{\circ}$ ) compared with pure PLA, except at under extrusion for $90^{\circ}$, the density shows otherwise due to high viscosity and low fluidity at a temperature below its melting temperature. This result is consistent with the dimensional accuracy which was discussed earlier. In general, $90^{\circ}$ infill line direction represents the highest density value by almost $2.112 \mathrm{~g} / \mathrm{cm}^{3}$ (for advanced PLA + ) at $195^{\circ} \mathrm{C}$ whereas $0^{\circ}$ infill line direction represents the lowest density value by almost $1.590 \mathrm{~g} / \mathrm{cm}^{3}$ (for advanced PLA+) at $220^{\circ} \mathrm{C}$. The overall density for pure PLA was 1.781 $\mathrm{g} / \mathrm{cm}^{3}$ (more dense regions) and $1.667 \mathrm{~g} / \mathrm{cm}^{3}$ (less dense regions) for advanced PLA+. As a consequence, pure PLA resulted in stronger microstructure and more rigid sample to the deformation system.

\section{Conclusions}

Experimental investigations at the small scale level are necessary to understand the warping characteristics in FDM 3D of prototypes. This work addressed the motivation of studying the warping deformation and dimensional accuracy of two printing materials: pure PLA and advanced PLA+ at $0^{\circ}, 90^{\circ}, 45^{\circ}$ and $\pm 45^{\circ}$ infill line direction, and the following conclusions were drawn from the present study:

- The overall mean size of the rectangular printed parts in length and width reduced to $63.4362 \mathrm{~mm} \times$ $9.5201 \mathrm{~mm}$ (for pure PLA) and $63.4362 \mathrm{~mm} \times$ $9.5189 \mathrm{~mm}$ (for advanced PLA+) after printed and drying, showing less than $0.1 \%$ reduction, respectively. However, the size of the rectangular printed parts in height increased to $3.2687 \mathrm{~mm}$ (for pure PLA) and $3.2779 \mathrm{~mm}$ (for advanced PLA+) after printing and drying, showing less than $0.1 \%$ reduction, respectively. This indicates a volumetric increase by $1.9767 \%$ (for pure PLA) and $2.2311 \%$ (for advanced PLA+), compared to the original STL file.

- The error in accuracy observed in the final part of FDM 3D printed products arises from shrinkage during cooling and solidification or warping as uneven heat distribution creates internal stresses within a part.

- The infill line direction does have a substantial effect on warping.

- The dimensional precision of FDM 3D printed parts is quite good, considering the diameter of the depositing material. However, the dimensional deviations (dimensional tolerances) were affected by the nozzle temperature.

From the amount of data presented, it is concluded that different FDM 3D printing processing parameters can have a significant effect on WD, DA and density. Therefore, there is a significant linear effect of nozzle temperature on WD, DA and density.

\section{Conflicts of Interest}

The authors have no conflicts of interest.

\section{Funding Source}

The authors received no financial support for the research and/or for the publication of this article.

\section{Availability of Data and Materials}

The data analyzed for this manuscript is the part of our research work and is available for public users.

\section{References}

[1] Nazan, M.A., et al., An exploration of polymer adhesion on 3D printer bed. IOP Conference Series: Materials Science and Engineering, 2017. 210(1): p. 012062.

[2] Fafenrot, S., et al., Three-Dimensional (3D) Printing of PolymerMetal Hybrid Materials by Fused Deposition Modeling. Materials (Basel, Switzerland), 2017. 10(10): p. 1199.

[3] Jain, R.K. and V.K. Jain, Optimum selection of machining conditions in abrasive flow machining using neural network. Journal of Materials Processing Technology, 2000. 108(1): p. 62-67.

[4] Casavola, C., et al., Residual stress measurement in Fused Deposition Modelling parts. Polymer Testing, 2017. 58: p. 249-255.

[5] ASTM-F2792-12a, Standard Terminology for Additive Manufacturing Technologies, in ASTM International. 2012, ASTM: West Conshohocken, PA, www.astm.org.

[6] Wani, A.M., V. Yadava, and A. Khatri, Simulation for the prediction of surface roughness in magnetic abrasive flow finishing (MAFF). Journal of Materials Processing Technology, 2007. 190(1): p. 282-290.

[7] Hull, C.W., Apparatus for production of three-dimensional objects by stereolithography. 1986, Google Patents.

[8] Alsoufi, M.S. and A.E. Elsayed, How Surface Roughness Performance of Printed Parts Manufactured by Desktop FDM 3D Printer with PLA+ is Influenced by Measuring Direction. American Journal of Mechanical Engineering, 2017. 5(5): p. 211-222.

[9] Alsoufi, M.S. and A.E. Elsayed, Quantitative analysis of $0 \%$ infill density surface profile of printed part fabricated by personal FDM $3 D$ printer International Journal of Engineering \& Technology, 2018. 7(1): p. 44-52.

[10] Alsoufi, M.S. and A.E. Elsayed, Surface Roughness Quality and Dimensional Accuracy - A Comprehensive Analysis of $100 \%$ Infill Printed Parts Fabricated by a Personal/Desktop Cost-Effective FDM 3D Printer Materials Sciences and Applications, 2018. 9(1): p. 11-40.

[11] Fletcher, A.J., et al., Computer Modelling of the Abrasive Flow Machining Process, in Surface Engineering, S.A. Meguid, Editor. 1990, Springer Netherlands: Dordrecht. p. 592-601.

[12] Ko, S.L., Y.M. Baron, and J.I. Park, Micro deburring for precision parts using magnetic abrasive finishing method. Journal of Materials Processing Technology, 2007. 187-188: p. 19-25.

[13] Galantucci, L.M., F. Lavecchia, and G. Percoco, Experimental study aiming to enhance the surface finish of fused deposition modeled parts. CIRP Annals - Manufacturing Technology, 2009. 58(1): p. 189-192

[14] Conner, B.P., et al., Making sense of 3-D printing: Creating a map of additive manufacturing products and services. Additive Manufacturing, 2014. 1-4: p. 64-76.

[15] Spoerk, M., et al., Shrinkage and Warpage Optimization of Expanded-Perlite-Filled Polypropylene Composites in ExtrusionBased Additive Manufacturing. Macromolecular Materials and Engineering, 2017. 302(10): p. 1700143.

[16] Alafaghani, A.a., A. Qattawi, and M.A. Ablat, Design Consideration for Additive Manufacturing: Fused Deposition Modelling. Open Journal of Applied Sciences, 2017. 7(6): p. 291-318.

[17] Mostafa, M.A.G., M.S. Alsoufi, and B.A. Tayeb, CAD/CAM Integration Based on Machining Features for Prismatic Parts. 
International Journal of Emerging Trends \& Technology in Computer Science 2015. 4(3): p. 106-110.

[18] Too, M.H., et al., Investigation of $3 D$ Non-Random Porous Structures by Fused Deposition Modelling. The International Journal of Advanced Manufacturing Technology, 2002. 19(3): p. $217-223$.

[19] Masood, S.H., W. Rattanawong, and P. Iovenitti, Part Build Orientations Based on Volumetric Error in Fused Deposition Modelling. The International Journal of Advanced Manufacturing Technology, 2000. 16(3): p. 162-168.

[20] Bell, C., Maintaining and Troubleshooting Your 3D Printer. 2014: Apress. 528.

[21] Loveless, T.R., R.E. Williams, and K.P. Rajurkar, A study of the effects of abrasive-flow finishing on various machined surfaces. Journal of Materials Processing Technology, 1994. 47(1): p. 133-151.

[22] Jones, R., et al., RepRap - the replicating rapid prototyper. Robotica, 2011. 29(1): p. 177-191.

[23] Kentzer, J., et al. An open source hardware-based mechatronics project: The replicating rapid 3-D printer. in 2011 4th International Conference on Mechatronics (ICOM). 2011.

[24] Alsoufi, M.S. and A.E. Elsyeed, Warping Deformation of Desktop $3 D$ Printed Parts Manufactured by Open Source Fused Deposition Modeling (FDM) System. International Journal of Mechanical and Mechatronics Engineering, 2017. 17(4): p. 7-16.

[25] Guerrero-de-Mier, A., M.M. Espinosa, and M. Domínguez, Bricking: A New Slicing Method to Reduce Warping. Procedia Engineering, 2015. 132: p. 126-131.

[26] Nazan, M.A., et al., Optimization of Warping Deformation in Open Source 3D Printer using Response Surface Method Proceedings of Mechanical Engineering Research Day 2016, 2016 p. 71-72.

[27] [Online]. Available: http://www.esunchina.net. [Accessed January 2, 2019].

[28] Yaman, U., Shrinkage compensation of holes via shrinkage of interior structure in FDM process. The International Journal of Advanced Manufacturing Technology, 2018. 94(5): p. 2187-2197.

(C) The Author(s) 2019. This article is an open access article distributed under the terms and conditions of the Creative Commons Attribution (CC BY) license (http://creativecommons.org/licenses/by/4.0/). 